IAF-94-R.1.362

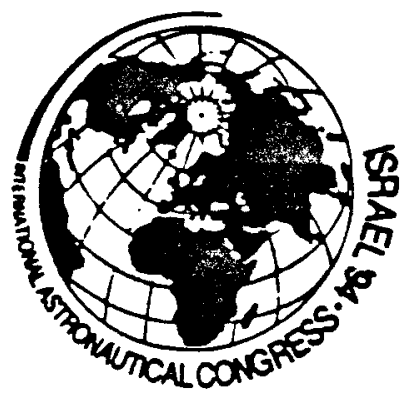

JERUSALEM ISRAEL

1994

\title{
Development and Use of the Galileo and Ulysses Power Sources
}

Gary L. Bennett

National Aeronautics and Space Administration

Washington, D. C. 20546 U.S.A.

Richard J. Hemler

Martin Marietta Astro Space

Philadelphia, PA 19101 U.S.A.

Alfred Schock

Fairchild Space Company

Germantown, MD 20874 U.S.A.

\section{5th CONGRESS OF THE INTERNATIONAL ASTRONAUTICAL FEDERATION \\ October 9-14, 1994 / Jerusalem, Israel}




\section{DISCLAIMER}

This report was prepared as an account of work sponsored by an agency of the United States Government. Neither the United States Government nor any agency Thereof, nor any of their employees, makes any warranty, express or implied, or assumes any legal liability or responsibility for the accuracy, completeness, or usefulness of any information, apparatus, product, or process disclosed, or represents that its use would not infringe privately owned rights. Reference herein to any specific commercial product, process, or service by trade name, trademark, manufacturer, or otherwise does not necessarily constitute or imply its endorsement, recommendation, or favoring by the United States Government or any agency thereof. The views and opinions of authors expressed herein do not necessarily state or reflect those of the United States Government or any agency thereof. 


\section{DISCLAIMER}

Portions of this document may be illegible in electronic image products. Images are produced from the best available original document. 


\title{
Development and Use of the Galileo and Ulysses Power Sources
}

\author{
Gary L. Bennett ${ }^{1}$, Richard J. Hemler ${ }^{2}$, and Alfred Schock ${ }^{3}$ \\ ${ }^{1}$ NASA Headquarters (retired); Permanent Address: \\ 1107 North 16 th Street; Bolse, Idaho 83702 ; U.S.A. \\ ${ }^{2}$ Martin Marletta Astro Space; P.O. Box 8555; Philadelphia, PA 19101; U.S.A. \\ ${ }^{3}$ Falrchlld Space Company; 20301 Century BIvd; Germantown, MD 20874; U.S.A.
}

\begin{abstract}
The Galileo mission to Jupiter and the Ulysses mission to explore the polar regions of the Sun required a new power source: the general-purpose heat source radioisotope thermoelectric generator (GPHS-RTG), the most powerful RTG yet flown. Four flight-qualitied GPHS-RTGs were fabricated with one that is being used on Ulysses, two that are being used on Galileo and one that was a common spare (and is now available for the Cassini mission to Saturn). In addition, an Engineering Unit and a Qualification Unit were fabricated to qualify the design for space through rigorous ground tests. This paper summarizes the ground testing and performance predictions showing that the GPHS-RTGs have met and will continue to meet or exceed the performance requirements of the ongoing Galileo and Ulysses missions.
\end{abstract}

\section{Introduction}

Both the NASA Galileo mission to explore the Jovian system and the European Space Agency's (ESA's) Ulysses mission to explore the polar regions of the Sun challenged the space power community leading eventually to

Copyright $\odot 1994$ by the American Institute of Aoronautics and Astronautics, Inc. No copyright is asserted in the United States under Title 17, U.S. Code. The U.S. Government has a royaltytree license to exercise all rights under the copyright claimed herein for Governmental purposes. All other rights are reserved by the copyright owner. a common solution: the general-purpose heat source radioisotope thermoelectric generator (GPHS-RTG). ${ }^{1-5}$ Both spacecraft were designed to fly to Jupiter: (1) Ulysses went there in February 1992 to use the immense Jovian gravity to twist its trajectory out of the plane of the ecliptic and into a polar path around the Sun and (2) Galileo will arrive in December 1995 to conduct a 20-month exploration in orbit around the largest planet in the solar system. The Galileo and Ulysses spacecraft along with the locations of their GPHS-RTGs are shown in Figures 1 and 2 respectively.

In selecting a power source for Galileo and Ulysses several daunting challenges had to be overcome: the solar energy flux at Jupiter is about 25 times less than it is at Earth, the temperatures are quite low $(\sim 130 \mathrm{~K})$, and the radiation belts are very severe. Fortunately the successful flights of the Pioneer 10 and 11 spacecraft and the Voyager 1 and 2 spacecraft to Jupiter and beyond had shown that RTGs could easily overcome these challenges. Originally, after some difficulties with a competing thermoelectric technology, the Galileo spacecraft was to use a modified version of the multi-hundred watt (MHW) RTG that powers the Voyager 1 and 2 spacecraft (as well as two U.S. Air Force [USAF] satellites known as Lincoln Experimental Satellites 8 and 9 [LES 8/9]); however, the Galileo project eventually settled on the GPHSRTG, which had been designed for Ulysses, because of the improved specific power of the GPHS-RTG. 
From the conception of both programs in the late 1970s and throughout the early 1980s the Galileo and Ulysses missions went through a number of iterations and launch dates which impacted the design and testing of the GPHSRTGs. "Final" launch dates involving two separate Space Shuttle flights in May 1986 were eventually chosen for both spacecraft. The flight GPHS-RTGs were completed in time to meet these dates; however, the loss of the Challenger in January 1986 led to a delay of the Galileo launch to 18 October 1989 and to a delay of the Ulysses launch to 6 October 1990. These delays will be discussed later in terms of the impact on the power performance of the GPHS-RTGs.

For the originally planned May 1986 launches the power requirement for the Galileo mission was to provide at least 510 We with two GPHS-RTGs at 4.2 years $(36,800 \mathrm{~h})$ after beginning of mission (BOM) while the power requirement for the Ulysses mission was to provide at least 250 We with one GPHS-RTG at 4.7 years $(41,200 \mathrm{~h}$ ) after BOM. (The Galileo RTGs operate at $30 \mathrm{~V}$ and the Ulysses RTG operates at $28 \mathrm{~V}$.) As a result of the launch delay and the changed mission trajectory the power requirement for the Galileo RTGs was changed to $470 \mathrm{We}$ (235 We per RTG) at end of mission (EOM) $(71,000 \mathrm{~h}$ after BOM). In the case of Ulysses the power requirement was changed to 245 We after $42,000 \mathrm{~h}$. (For comparison with the MHWRTGs, which are based on identical thermoelectric technology, and, which were, until 1989, the most powerful RTGs flown, the USAF LES $8 / 9$ spacecraft required 125 We per RTG at EOM [5 years after launch] and the NASA Voyager $1 / 2$ spacecraft required 128 We minimum per RTG at EOM [ 4 years after launch].)

This paper provides an overview of the development and testing program involving an electrically heated Engineering Unit, a nuclear-heated Qualification Unit (known as Q-1), and four flight RTGs designated F1, F3, F4, and F5. (The F2 converter was an unfueled spare and is planned to be used on the Cassini spacecraft.) Flight RTGs $F 1$ and $F 4$ are on Galileo and F3 is on Ulysses. Flight RTG F5 was a common spare and is planned to be used on the Cassini spacecraft.

\section{GPHS-RTG Description}

As noted earlier the GPHS-RTG design is built upon the successful technology used in the four MHW-RTGs (two each) flown on the USAF LES $8 / 9$ satellites and the six MHWRTGs (three each) flown on the Voyager $1 / 2$ spacecraft. These ten MHW-RTGs have performed flawlessly in space for over 18.5 years in the case of LES $8 / 9$ and over 17 years in the case of Voyagers $1 / 2$. The GPHSRTG was designed to convert about $4410 \mathrm{Wt}$ from the nuclear heat source into at least 285 We at BOM. The GPHS-RTG case allows for attachment to the spacecraft and, through supporting structure, tandem attachment of additional RTGs. The GPHS-RTG is configured for Space Shuttle launches and is designed to withstand the launch and ascent dynamic environment. The GPHS-RTG program included the most extensive safety analysis and testing of any U.S. RTG yet flown. Reference 6 describes the process leading to the GPHS-RTG design.

The GPHS-RTG consists of two major components: the general-purpose heat source (GPHS) and the converter which includes the thermopile that converts the radioisotopegenerated thermal power into electrical power. A conceptual drawing of the GPHSRTG is presented in Figure 3, which shows a cutaway portion of the converter to illustrate its internal construction and the position of the 18 GPHS modules comprising the radioisotope heat source. The converter and heat source are discussed in the next subsections.

\section{GPHS Converter}

The GPHS-RTG converter design is composed of an aluminum alloy (type 2219) outer case (nominal thickness $1.5 \mathrm{~mm}$ ) with aluminum alloy pressure domes, an active converter housing cooling system (ACS), heat source supports, thermoelectric assemblies attached to the outer shell, and the molybdenum/astroquartz $\left(\mathrm{SiO}_{2}\right)$ multifoil insulation peripheral and end assemblies. Overall diameter of 
the converter with fins is $42.2 \mathrm{~cm}$ and the length is $114 \mathrm{~cm}$. A gas management system mounted externally to the outer shell is provided for charging the assembly with inert gas for ground operation and for venting the gas into space after launch. The GPHS-RTG will provide partial power (at least $226 \mathrm{We}$ ) on the launch pad with the inert cover gas. The outer case is coated with a $50.8-\mu \mathrm{m}$-thick electrically conductive silicone paint to provide an emissivity of 0.9 . The ACS, which consists of tubular passages near the base of each fin, permits water circulation to remove approximately $3500 \mathrm{Wt}$ thereby limiting the prelaunch thermal power radiated from the converter surface to the Shuttle bay and sensitive spacecraft instruments.

The thermopile consists of 572 silicon-germanium ( $\mathrm{SiGe}$ ) alloy thermoelectric elements called "unicouples" connected in a seriesparallel network. The thermopile insulation consists of an insulation canister and end caps composed of 60 layers of $7.6-\mu \mathrm{m}$ molybdenum foil with astroquartz cloth separators and a molybdenum frame assembled in the shape of an octagonal prism with joints designed to accommodate thermal expansion. The unicouple, shown schematically in Figure 4 , is identical in design to that used in the MHW-RTGS flown on LES $8 / 9$ launched in 1976 and Voyagers 1/2 launched in 1977. 7-9

The unicouples are individually bolted to the outer aluminum case and arranged in 16 circumferential rows. The unicouples are supported in a cantilever fashion from the outer case and, in turn, the unicouples support the insulation packet. The converter uses two series-parallel electric wiring circuits in parallel to enhance reliability and to provide the required output voltage. The circuit will continue to operate even if a unicouple fails in either the open or short circuit mode. The circuit loops are also arranged to minimize the net magnetic field of the generator. 8,9

The unicouple consists of an 85 weight percent ( 95 atom percent) silicon in a silicon molybdenum (SiMo) alloy electrical connector and heat collector, or hot shoe, to which the $\mathrm{N}$ and $\mathrm{P}$ couple legs are bonded. The $\mathrm{N}$ and $P$ legs are equal in size, $2.74 \mathrm{~mm} \times 6.50 \mathrm{~mm}$ in cross section, with a total length of 20.3 $\mathrm{mm}$. The couple height is $31.1 \mathrm{~mm}$ and the hot shoe measures $22.9 \mathrm{~mm} \times 22.9 \mathrm{~mm}$ and is $1.9 \mathrm{~mm}$ thick. Two compositions of SiGe are used in the legs: 78 atom percent silicon for most of the length and a short $(3.18 \mathrm{~mm})$ 63.5 atom percent section at the cold end. The lower content segment is used to provide improved matching for thermal expansion of the bonded parts. The two SiGe legs and their corresponding sections of the hot shoe are doped to provide thermoelectric polarity: the $\mathrm{N}$-type material is doped with phosphorus and the P-type with boron. The dopant level is $\sim 10^{20}$ carriers per $\mathrm{cm}^{3}$ ( 0.1 atom percent). The silicon alloy couple is bonded to a cold stack assembly of tungsten, copper, and alumina parts which separate the electrical and thermal currents. The thermal current crosses the alumina insulator and passes through the radiator attachment into the outer shell. The electric current between couples is shunted through separate copper straps bonded to each leg assembly. The straps are riveted together in the space between the inside of the outer case and the outside of the insulation system to form the thermopile electrical circuit. The unicouples are electrically insulated and mechanically cushioned from the multifoil insulation by three layers of astroquartz yarn (nominal diameter of $0.76 \mathrm{~mm}$ ) wound tightly around the two SiGe legs of each couple and by an alumina water beneath the hot shoe. A silicon nitride $\left(\mathrm{Si}_{3} \mathrm{~N}_{4}\right)$ coating approximately $1-\mu \mathrm{m}$ thick is applied to the unicouple legs and hot shoes to retard silicon sublimation. The unicouples operate at a nominal $1273 \mathrm{~K} / 573 \mathrm{~K}$ hot junction/cold junction in a vacuum environment. The corresponding nominal hot shoe temperature is $1308 \mathrm{~K}^{10,11}$

During ground operations the interior of the generator is pressurized to $172 \mathrm{kPa}$ absolute with an inert gas (normally argon for testing and storage and xenon at launch) to prevent oxidation of the molybdenum foils and graphite surfaces. After launch the xenon is vented through a pressure relief device (PRD) and 
the power output rises to its design value. ${ }^{11}$ The results of tests conducted in argon, xenon, and vacuum will be presented in the section on performance tests.

\section{General-Purpose Heat Source}

The GPHS, shown in Figure 5, supplies the thermal power to the thermoelectric converter from a single column of 18 independent modules. The modules are each in the shape of a rectangular parallelepiped, having dimensions $93.17 \mathrm{~mm}$ by $97.18 \mathrm{~mm}$ by $53.08 \mathrm{~mm}$, a mass of about $1.43 \mathrm{~kg}$, and a thermal output at the originally planned launch of approximately 245 Wt.

Safety considerations were key factors in the design of the GPHS. The principal safety objective is to keep the radioisotope fuel contained or immobilized to prevent inhalation or ingestion by humans and consequent exposure of the internal organs and bones to radiation. $^{12}$ The modularity of the GPHS design reduces the potential source term from postulated events such as projectile impacts. The GPHS was originally designed to accommodate a range of potential radioisotope power system applications. One of the motivations for its development was the expectation that once it had been qualified for use in space it could be employed in future missions without extensive requalification. $^{13-15}$

Each GPHS module contains four plutonia fuel pellets of nominal thermal inventory of 62.5 Wt. The plutonium is enriched to about $83.5 \%{ }^{238} \mathrm{Pu}$. The original GPHS thermal power requirement of $4410 \mathrm{Wt}$ translates into about $8.1 \mathrm{~kg}$ of ${ }^{238} \mathrm{Pu}$ per generator. Tests in the MHW program showed the basic compatibility of the materials (plutonia, iridium, carbon) used in the GPHS. ${ }^{13-16}$

The physical form of the fuel is a cylindrically shaped, ceramic pellet of average diameter $27.53 \mathrm{~mm}$ and average length of $27.56 \mathrm{~mm}$. Each pellet is individually contained in an oxidation-resistant post-impact containment shell or cladding made from an alloy of iridium. Two of these "fueled clads" are encased in a graphite impact shell machined from Fine Weave Pierced Fabric (FWPF) ${ }^{\mathrm{TM}}$, which is a 3-D carbon-carbon composite material produced by AVCO Corporation, designed to provide impact protection for the fueled clads under impact conditions associated with GPHS module terminal velocity. Two of these graphite impact shell assemblies are inserted into an aeroshell also machined from FWPFTM which is designed to provide aerothermodynamic protection during a postulated reentry. A thermally insulative graphite sleeve made of carbon-bonded, carbon fiber (CBCF) fits between each graphite impact shell assembly and the aeroshell and serves to control the temperature of the iridium cladding during a postulated reentry/impact accident. ${ }^{15,16}$

The GPHS has been through the most extensive safety analysis and testing program of any RTG flown and has successfully passed independent safety review and achieved Presidential launch approval for Galileo and Ulysses. $^{16-18}$

\section{Performance Tests}

Management of the GPHS-RTG team, which spanned four contractors and seven government laboratories, was implemented through a small, proactive program/project office 10cated at DOE Headquarters. ${ }^{19}$ The design of the GPHS-RTG was controlled by the interface documents and specification requirements established by the U.S. Department of Energy (DOE) and NASA as represented by the Galileo and Ulysses project offices located at the Jet Propulsion Laboratory (JPL). Performance requirements for the GPHS-RTG were dictated by the spacecraft requirements and the launch vehicles (Space Shuttle originally with Centaur upper stage). The principal requirements were levied on power (at launch, BOM, EOM); structural (ability to withstand launch vibrations and pyrotechnic shock); magnetic field strength; mass properties (mass, center of mass, moments of inertia, products of inertia); pressurization; nuclear radiation; and 
general functional attributes (insulation resistance, internal resistance, pressure decay, nonsusceptibility to electrostatic discharging).

\section{Test Phllosophy}

The test philosophy employed throughout the GPHS-RTG program was to build and test hardware through increasing levels of assembly. First unicouples were built and tested, followed by the testing of six 18-couple modules. The full-scale Component Engineering Test (CET) units were built and tested for structural and mass properties. Next came the assembly and testing of the electrically heated Engineering Unit, which proved the design, and the nuclear-heated Qualification Unit, which qualified the overall RTG design. Finally, the four flight RTGs were assembled and tested. Supporting this test program were engineering analyses, component testing and materials characterizations. $9,11,20$

The general sequence of tests performed on the flight RTGs is shown diagrammatically in Figure 6. 21,22 The Engineering Unit and the Qualification Unit were subjected to flight acceptance (FA) and type acceptance (TA) vibrations. During the TA vibrations the dynamic environments were $50 \%$ more severe in amplitude and longer in duration than the expected launch environment. The successful completion of the TA vibration tests demonstrated that the GPHS-RTG design had more than sufficient structural strength margin. ${ }^{21}$

A comparison of the exterior configurations of the Qualification Unit and a flight RTG is shown in Figure 7. (The Engineering Unit configuration was similar to that shown for the Qualification Unit.) The principal difference between the Qualification Unit and a flight RTG was the spool piece assembly attached to the former which permitted extensive internal instrumentation for diagnostic purposes. In the case of the Engineering Unit the spool piece also allowed connection of electrical power leads for the electric heat source (EHS). 21

\section{Converter Performance}

Each converter was tested by applying heat from the EHS in a vacuum environment with the results shown in Table 1 . The beginningof-life (BOL) power was normalized to a heat input of $4400 \mathrm{Wt}$ by using a computed adjustment of $0.12 \mathrm{We} / \mathrm{Wt}$. The shunt resistance provided a measure of the integrity of the electrical isolation or insulation system since it represents the insulation resistance between the thermoelectric circuit and the outer case. The requirements was to have an isolation greater than 1,000 ohms. From tests run on the Engineering Unit it was determined that if a generator produced at least 130 We with an internal argon atmosphere then the generator would produce at least 200 We of prelaunch power when filled with the less conductive xenon after accounting for degradation losses.

In order to meet the RTG mass requirement of $\leq 56.2 \mathrm{~kg}$ the converter mass target was set at $\leq 30.4 \mathrm{~kg}$. A leak test was run on each converter to ensure that it could meet the basic requirement of remaining positively pressurized (> $3.4 \mathrm{kPa}$ gauge) for 30 days on-pad after being initially pressurized to $172 \mathrm{kPa}$ absolute.

Table 1 shows that all of the flight converters met the acceptance criteria.

Following Figure 6, the next step was to insert the 18 GPHS modules and measure the performance of each converter as part of an RTG.

\section{InItlal RTG Functlongl Performance}

Initial RTG functional performance measurements were made before the end dome was attached to each RTG and before each RTG was removed from the assembly chamber. These performance measurements included power output, load voltage, open circuit voltage, current, internal resistance, isolation ("insulation") resistance, average outer case temperature (requirement $\leq 533 \mathrm{~K}$ ) as measured by resistance temperature devices (RTDs) and bell jar temperature. These 
measurements were performed in an argon atmosphere and again in vacuum, thereby providing initial data on the expected RTG performance on-pad and at BOM. 21,22

Following assembly, each RTG was put through a series of pre-vibration functional tests while filled with argon and in an air environment to establish a performance baseline before vibration testing. In addition to the previously listed measurements a pressure decay measurement was made. All of the generators met their initial functional performance requirements. 21,22

\section{Vibratien Performance}

Vibration tests were run on CET-1, the Engineering Unit, the Qualification Unit, and each of the flight RTGs. The initial test of the Engineering Unit led to a minor redesign--the replacement of four unicouples (leaving a total of $\mathbf{5 7 2}$ unicouples) by inner insulation frame supports. This was accomplished while still meeting the power requirements.

A common set of dynamic test environments with appropriate notching was developed to encompass the different mounting configurations used on the Galileo and Ulysses spacecraft (see Figures 1 and 2). In addition to random vibration and transient vibration tests, the Engineering Unit was subjected to acoustic testing and pyrotechnic shock testing. The Engineering Unit successfully passed these tests thereby verifying the GPHS-RTG design concept for these environments.

The generalized sequence of the vibration tests of the flight RTGs was as follows: 21,22

\begin{tabular}{|c|c|c|c|}
\hline Iest & Axis & Environment & Duration \\
\hline 1 & $\mathbf{Y}$ & $1 / 2$ G sine sweep & $\begin{array}{l}10-2000 \mathrm{~Hz} \\
2 \mathrm{Oct} . / \mathrm{min} .\end{array}$ \\
\hline 2 & $\mathbf{Y}$ & FA random & $1 \mathrm{~min} . @ 0 \mathrm{~dB}$ \\
\hline 3 & $\mathbf{Y}$ & FA transients & $\begin{array}{l}1 \text { pulse @0 dB } \\
4 \text { frequencies }\end{array}$ \\
\hline 4 & $\mathbf{Y}$ & $1 / 2$ G sine sweep & $\begin{array}{l}10-2000 \mathrm{~Hz} \\
2 \text { Oct./min. }\end{array}$ \\
\hline 5 & $\mathbf{Z}$ & $1 / 2 \mathrm{G}$ sine sweep & $\begin{array}{l}1 \mathrm{~min} . @ 0 \mathrm{~dB} \\
2 \mathrm{Oct} . / \mathrm{min} .\end{array}$ \\
\hline
\end{tabular}

$\begin{array}{llll}6 & \mathrm{Z} & \text { FA random } & 1 \text { min. @ 0 dB } \\ 7 & \mathrm{Z} & \text { FA transients } & \begin{array}{l}1 \text { pulse @0 dB } \\ 4 \text { frequencies }\end{array} \\ 8 & \mathrm{Z} & 1 / 2 \mathrm{G} \text { sine sweep } & \begin{array}{l}10-2000 \mathrm{~Hz} \\ 2 \text { Oct./min. }\end{array}\end{array}$

Regarding the duration, the frequencies (and amplitudes shown in parentheses) selected were

Y-axis (lateral axis): $15.75 \mathrm{~Hz}(6.5 \mathrm{G})$, $31.50 \mathrm{~Hz}(4.8 \mathrm{G}), 50.00 \mathrm{~Hz}(6.9 \mathrm{G}), 79.73$ $\mathrm{Hz}(6.0 \mathrm{G})$

Z-axis (longitudinal axis): $15.75 \mathrm{~Hz}(6.5$ G), $25.00 \mathrm{~Hz}(12.0 \mathrm{G}), 63.00 \mathrm{~Hz}(6.0 \mathrm{G})$, $100.00 \mathrm{~Hz}(4.5 \mathrm{G})$

The Engineering Unit and the Qualification Unit were subjected to TA random vibration and TA transient vibration tests after the FA tests. With the exception of the transient vibration environment, these are conventional environments normally encountered in the qualification testing of spacecraft equipment. ${ }^{11}$

The power spectral density distributions of random vibration applied at the inboard mounts during lateral axis and longitudinal axis tests of the F3 RTG are shown in Figures 8 and 9 . The spectra were derived from the results of the RTG qualification tests with modifications to suit flight RTGs as determined from $\mathrm{F} 1$ testing. ${ }^{23}$ The test spectra applied during $\mathrm{F} 3$ vibration testing were identical to those applied to F1, F4, and F5. Figures 8 and 9 show that the applied random spectra were within the $\pm 3 \mathrm{~dB}$ tolerance bands of the defined environment. No significant changes occurred in the performance of any of the RTGs during the random vibration tests. ${ }^{23-27}$

The FA transient test frequency and amplitude requirements are listed in the note following the tabulation of the generalized sequence of vibration tests. The listed amplitudes were selected for acceptance testing based on the amplification factors measured during qualification testing of the Qualification Unit. These factors were intended to limit the flight 
ATG responses to those specified for acceptance testing $(27 \mathrm{G}$ at the outboard end and 15 $G$ at the center of mass in the lateral direction; $20 \mathrm{G}$ at the heat source and $22 \mathrm{G}$ at the inner frame in the longitudinal direction). As a typical example, Figure 10 shows the measured normalized test pulse for F3 at 15.84 Hz superimposed on upper and lower limit envelopes. 24 The measured shock response spectrum for $\mathrm{F} 3$ at $15.84 \mathrm{~Hz}$ is shown in Figure 11.24 Similar plots were developed for each flight RTG over the range of transient test pulses. No significant changes occurred in the performance of any of the RTGs during the transient vibration tests. ${ }^{23-27}$

The criteria for satisfactorily demonstrating the ability of an RTG to withstand these environments was the observation of no visual damage and meeting the post-vibration functional test requirements. The visual observations for damage were augmented by a qualitative evaluation of each RTG's response to pre- and post-test low-level sine sweeps and by monitoring each RTG's performance during the dynamic testing. There was no evidence for structural damage during the FA vibration tests.

Following vibration, functional tests were run to determine power, isolation ("insulation") resistance, internal resistance, and pressure decay. A key requirement was that the change in the internal circuit resistance from one functional test to another had to be less than $0.008 \mathrm{ohm}$, exclusive of temperature and aging effects. All of the RTGs met this requirement. Meeting this requirement provided added assurance that the unicouples were integral since one broken unicouple will cause an increase of $0.008 \mathrm{ohm}$ in the internal resistance.

The critical load conditions for Ulysses and Galileo are summarized in Tables 2 and 3 respectively, showing that the RTGs meet the required structural integrity. The ACS was also successfully tested during the vibration testing.
Magnetlc Performance

Table 4 shows a typical RTG magnetic field. Measurements were made on F1 with sensors located at distances of 1 meter and 1.5 meter and at increments of $30^{\circ}$ in the $X-Z$ and $Y-Z$ planes of the RTG. An estimate of the field at 2 meters was made by extrapolation of the 1.5meter measurements assuming an inverse cubic relation with distance. ${ }^{23}$ The magnetic field was not a constraint on the Galileo mission; however, compensation magnets were added to the Ulysses RTG (F3) to correct for an uncompensated current loop in the converter.

\section{Mass Propertles}

The mass of each flight RTG was required to be $\leq 56.2 \mathrm{~kg}$. The mass was determined by measuring the RTG gross mass and subtracting the masses of any non-flight items installed on the RTG. Table 5 presents a summary of the mass properties for the flight RTGs. Two entries showing the presence and absence of the Ulysses compensation magnets are given for F4 because F4 was originally intended to be the common spare RTG. The F3 data include the effects of the compensation magnets. In all cases the flight RTGs met the requirements for mass properties. ${ }^{23-26}$

\section{Nuclear Radlation}

For the Qualification Unit there was a requirement that the neutron emission rate from the unshielded RTG should not exceed 7.0 $\times 10^{3}$ neutrons/(second)(gram of ${ }^{238} \mathrm{Pu}$ ). The use of an oxygen-16 exchange process during the production of the fuel pellets minimized the neutron emission rate by reducing the other isotopes of oxygen which produce neutrons from alpha-neutron reactions. The measurements for the Qualification Unit resulted in a neutron emission rate of $5.9 \times 10^{3}$ $\mathrm{n} / \mathrm{s}-\mathrm{g}\left({ }^{238} \mathrm{Pu}\right) \mathrm{.}^{27}$

There was no specific criterion for the flight RTGs but it was desired that the measurements from the flight RTGs be comparable 
with those made on the Qualification Unit. Figure 12 shows there was good agreement in neutron dose rates among the four flight RTGs and the Qualification Unit for measurements taken at $\theta=0^{\circ}$ (at midspan) and $\theta=90^{\circ}$. A similar agreement on the gamma radiation measurements can be seen in Figure $13 .^{24}$

\section{Thermal Vacuum Tests}

The thermal vacuum test provided the basis for the power projections, both BOM and EOM, for each RTG. Each flight RTG provided electrical power under simulated space conditions from 6 hours to over 40 hours in the thermal vacuum chamber at a pressure of $\leq 0.1 \mathrm{mPa}$ and an average sink temperature of $\sim 309 \mathrm{~K}$. Following the thermal vacuum test, each RTG was backfilled with argon for a six-hour performance and pressure decay test. 28

The thermal vacuum performance for each of the four flight RTGs is shown in Table 6. F4, which was originally planned to be the spare RTG, was tested twice, once under Galileo load conditions (30 V) and once under Ulysses load conditions $(28 \mathrm{~V})$. The thermal inventory of the GPHS is shown for the indicated date of completion of the thermal vacuum test. Three power outputs are shown: the actual measured power, the power corrected for losses in the connector resistance, and the power normalized to $4410 \mathrm{Wt}$. All four flight RTGs met the performance requirements. 28,29

\section{Post-Thermal-Vacuum Functional Test}

Upon completion of the thermal vacuum test for each RTG, measurements were made of power, insulation resistance, internal resistance and pressure decay to demonstrate that the RTG had not been degraded by the thermal vacuum environment. Each RTG met the power requirement (> $130 \mathrm{We}$ ) for an argon fill thus ensuring proper on-pad power. (The measured powers ranged from 166 We for F1 to 178 We for F3.) The internal resistance change (< 0.008 ohm) showed no evidence of broken unicouples and the RTGs demonstrated their ability to maintain the desired pressure from the cover gas for over 30 days unattended (estimates placed the capability at $>300$ days).

\section{Power Projectlens}

The RTG power output is defined to be the power at the RTG power connector pins which means that a correction must be made to account for connector resistance. Power projections were initially made from the test results given in Table 6 using the process illustrated in Figure 14 . The current-voltagepower (I-V-P) characteristics of the Qualification Unit are shown in Figure 15. Note that the $28-\mathrm{V}$ and $30-\mathrm{V}$ operating levels are near the peak power points. Long-duration power testing of the Engineering Unit and the Qualification Unit was conducted to validate performance models. $^{21,} 32$

\section{Mechanisms Affecting Power}

The largest contributor to power decay with time is the decay of the plutonium-238 radioisotope fuel. This radioisotope decay can be predicted with a high degree of accuracy. The next two most important factors are (1) dopant precipitation during storage which causes an increase in both resistivity and Seebeck coefficient which in turn results in a net power loss and (2) thermal conductivity decreases during storage which increase the open circuit voltage thereby leading to an increased power output. 28,30

Martin Marietta Corporation (MMC) has developed a computer model known as TEG32 based on an earlier model developed for the Apollo SNAP-27 RTGs and modified for the Voyager $1 / 2$ and LES $8 / 9$ MHW-RTGs. In order to account for the effects of dopant precipitation and thermal conductivity changes during storage the model uses a concept known as "effective age" for each. For dopant precipitation the effective age $\left(T_{0}\right)$ has an inverse relationship with precipitation: the lower the effective age the more rapidly the precipitation process is occurring. For thermal conductivity changes the effective age (K) is an adjustable parameter different from $T_{0}$ that depends 
upon the storage time of the RTGs prior to launch. $^{31}$ These effective ages become important factors in the analysis because the Galileo and Ulysses RTGs experienced the longest storage times $(37,000 \mathrm{~h}$ to 45,000

h) of any SiGe RTGs yet flown. ${ }^{30}$ Fortunately, these effects are eventually "annealed" out once the RTGs are brought to their in-space operating temperatures.

One additional factor (heat sink temperature variation) affected the performance of the two Galileo RTGs. As a result of the Challenger accident the Centaur upper stage was replaced with the less powertul Inertial Upper Stage (IUS) which necessitated the use of a VenusEarth-Earth-Gravity-Assist (VEEGA) trajectory to provide the extra energy needed to reach Jupiter. Thus, the Galileo RTGs did not experience the decreasing temperatures originally planned but instead experienced almost two times the Earth solar insolation ("2 Suns") at Venus and then a peak when the spacecraft flew back by the Earth from the cooler regions of the asteroid belt.

\section{Galleo Power Performance}

The post-launch electric power performance of the Galileo RTGs is presented in Figure 16 along with the power requirements for the different phases of the mission. Initial reported telemetry power was 577 We or 9 We above the specification requirement. The "measured" power is calculated at the spacecraft bus by multiplying the measured current from each RTG by the constant bus voltage. The telemetry data are presented in the form of a step function because the telemetry system is configured such that a change of $0.04 \mathrm{~A}$ (or $1.2 \mathrm{We}$ at $30 \mathrm{~V}$ ) must occur before an actual change in output is indicated. The stated accuracy of the measured current is $\pm 1.2 \%$ which translates into $\pm 3 \mathrm{We}$ for the power from each RTG. Following a parametric analysis which factored in the longer storage times of the GPHS-RTGs compared to the MHW-RTGs, the lower bound from the TEG32 analysis was developed assuming $T_{0}=$

400 hours with $K=1500$ hours. $30,32-35$ The maximum power based on the Voyager ex- perience is also shown in Figure 16. From the performance and analysis to date the EOM $(71,000 \mathrm{~h})$ power is predicted to be $475 \mathrm{We}$ or $5 \mathrm{We}$ above the specification requirement of 470 We. As shown in Figure 16 a positive power margin is predicted throughout the mission.

\section{Ulysses Power Performance}

The post-launch electrical power performance of the Ulysses RTG is shown in Figure 17 along with the predicted power. The total power output of the RTG is not measured directly rather it is estimated from an algorithm which considers (1) the main bus current, (2) an internal power dump current; and (3) nominal power consumption values for ten spacecraft components if they are operating at the time. The uncertainty in measuring the current produces $a \pm 3.5 \mathrm{We}$ error band. The adjustments to account for component power consumption are based only on nominal values and can be as great as $33 \%$ of the RTG output power. In addition there is an uncertainty resulting from telemetry that is similar to the Galileo uncertainty $( \pm 0.5 \%)$. $^{33-35}$

Martin Marietta personnel have modeled the Ulysses RTG performance by using a combination of $T_{0}=300$ hours and $K=500$ hours. JPL personnel have used the power performance of the second MHW-RTG on LES 8 (which operates at a voltage of $26.5 \mathrm{~V}$ close to the $28 \mathrm{~V}$ of the Ulysses RTG) as a predictor of the performance of the Ulysses RTG. Initial telemetry power was reported to be $289 \mathrm{We}$ which exceeded the specification requirement of $277 \mathrm{We}$. (The prelaunch prediction of BOM power was in the range of 282 We to 287 We.) Using either the Martin Marietta model or the JPL analysis it can be seen from Figure 17 that the Ulysses RTG will essentially meet the specification requirement of 245 We after 42,000 h. $^{33-35}$

Comparison of Flloht sllcon-Germanlum Data

Figure 18 provides a comparison of all avail- 
able flight data on silicon-germanium RTGs (MHW-RTGs and GPHS-RTGs) and the ground-test Qualification Unit $(Q-1)$ of the GPHS-RTG normalized to a common ratio of power as function of time (P) divided by the initial power $\left(P_{0}\right)$. To date, the combination of all unicouples in space has demonstrated about $\mathbf{5 5 0}$ million unicouple-hours of successful operation. The Galileo GPHS-RTGs are performing within the measured data band for the MHW-RTGs and the Ulysses GPHS-RTG is projected to meet the EOM power requirement. $^{33-37}$

\section{Summary and Conclusions}

Four flight RTGs (three flight RTGs and a common spare) were successfully assembled and tested for use on the Galileo and Ulysses spacecraft. The three GPHS-RTGs in use on the Galileo and Ulysses spacecraft have met all power performance requirements to date. Based on this performance and the extensive data base and modeling for silicon-germanium RTGs it is concluded that the GPHS-RTGs on Galileo and Ulysses will meet or exceed the remaining power performance requirements for the two missions.

\section{Acknowledgments}

The authors acknowledge with deep thanks the many contributions made by the staff members of Martin Marietta Astro Space, EG\&G Mound Applied Technologies, Savannah River Plant and Laboratory, Los Alamos National Laboratory, Oak Ridge National Laboratory, Sandia National Laboratories, Ames Laboratory, Fairchild Space Company, NUS Corporation, the Applied Physics Laboratory, Westinghouse Hanford Company, and Battelle Columbus Laboratories in the design, analysis, fabrication and testing of the GPHS-RTGs and their components.

\section{References}

1. Project Galileo, Mission and Spacecraft Design, JPL D-0518, Jet Propulsion Laboratory, Pasadena, California. Compilation of papers presented at the Galileo Session of the
AlAA 21st Aerospace Sciences Meeting held in Reno, Nevada, 10-13 January 1983.

2. C. M. Yeates, T. V. Johnson, L. Colin, F. P. Fanale, L. Frank, and D. M. Hunten, GALILEO: Exploration of Jupiter's System, NASA SP. 479, National Aeronautics and Space Administration, Washington, D. C. (1985).

3. G. L. Bennett, "Return to Jupiter", Astronomy, 15(5), pp. 14-22 (January 1987).

4. K.-P. Wenzel, R. G. Marsden, and B. Battrick, The International Solar Polar Mission -- Its Scientific Investigations, ESA SP. 1050, European Space Agency, Paris, France (July 1983).

5. G. L. Bennett, "Rendezvous with a Star", Sky \& Telescope, 80(5), pp. 496-498 (November 1990).

6. A. Schock, A. Shostak, and H. Sookiazian, "Design, Analysis, and Optimization of RTG for Solar Polar Mission", Proceedings of the 14th Intersociety Energy Conversion Engineering Conference, held in Boston, Massachusetts, 5-10 August 1979 (also published as FSEC-ESD-217-79/164, Fairchild Space Company, Germantown, Maryland), pp. 1444 $-1454$.

7. G. L. Bennett, J. J. Lombardo, and B. J. Rock, "Development and Use of Nuclear Power Sources for Space Applications," The Journal of the Astronautical Sciences, $\mathrm{XX|X}(4): 321$. 342 (October - December 1981).

8. R. D. Cockfield, R. F. Hartman, and C. E. Kelly, "RTG Power Sources for the International Solar Polar Mission", Proceedings of the 15th Intersociety Energy Conversion Engineering Conference, held in Seattle, Washington, 18-22 August 1980, pp. 10431046.

9. R. D. Cockfield, "Engineering Development Testing of the GPHS-RTG Converter", Proceedings of the 16th Intersociety Energy Conversion Engineering Conference, held in Atlanta, Georgia, 9-14 August 1981, pp. 
$321-325$.

10. C. E. Kelly, J. A. Loffreda, and R. Lorentzen, "Performance Models for the MHW Converter", 8th Intersociety Energy Conversion Engineering Conference Proceedings Addendum, held in Philadelphia, Pennsylvania, 13-16 August 1975, pp. 37-46.

11. C. E. Kelly and G. R. Ambrose, "Testing of the GPHS Electrically Heated Thermoelectric Converter", Proceedings of the 17th Intersociety Energy Conversion Engineering Conference, held in Los Angeles, California, 8-12 August 1982, pp. 1382-1386.

12. G. L. Bennett, "The Safety Review and Approval Process for Space Nuclear Power Sources", Nuclear Safety, 32(1), 1-18 (January - March 1991).

13. E. C. Snow and R. W. Zocher, GeneralPurpose Heat Source Development, Phase 1-. Design Requirements, LA-7385-SR, Los Alamos National Laboratory, Los Alamos, New Mexico (1978).

14. E. C. Snow, R. W. Zocher, I. M. Grinberg, and L. E. Hulbert, General-Purpose Heat Source Development, Phase II--Conceputal Designs, LA-7546-SR, Los Alamos National Laboratory, Los Alamos, New Mexico (1978).

15. A. Schock, "Design Evolution and Verification of the 'General-Purpose Heat Source'", Proceedings of the 15th Intersociety Energy Conversion Engineering Conference, held in Seattle, Washington, 18-22 August 1980, pp. 1032-1042.

16. G. L. Bennett et al., "Development and Implementation of a Space Nuclear Safety Program", Space Nuclear Power Systems 1987, edited by M. S. El-Genk and M. D. Hoover, Orbit Book Company, Malabar, Florida, pp. 59-92 (1988).

17. G. L. Bennett et al., "Update to the Safety Program for the General-Purpose Heat Source Radioisotope Thermoelectric Generators for the Galileo and Ulysses Missions", Space Nuclear Power Systems 1989, edited by M. S. El-Genk and M. D. Hoover, Orbit Book Company, Malabar, Florida, pp. 199-222 (1992).

18. J. A. Sholtis, Jr., D. A. Huff, L. B. Gray, N. P. Klug, and R. O. Winchester, "Technical Note: The Interagency Nuclear Safety Review Panel's Evaluation of the Ulysses Space Mission", Nuclear Safety, 32(4): 494-501 (1991).

19. G. L. Bennett, "Managing for Success: Examples and Observations from the GPHSRTG Program", Proceedings of the 28th Intersociety Energy Conversion Engineering Conference, held in Atlanta, Georgia, 8-13 August 1993, pp. 1.649-1.654.

20. G. L. Bennett, "The Past as Prologue: A Look at Historical Flight Qualifications for Space Nuclear Systems", IEEE AES Systems Magazine, 7(11): $26-36$ (November 1992).

21. G. L. Bennett, J. J. Lombardo, R. J. Hemler, and J. R. Peterson, "The General-Purpose Heat Source Radioisotope Thermoelectric Generator: Power for the Galileo and Ulysses Missions", Proceedings of the 21st Intersociety Energy Conversion Engineering Conference, held in San Diego, California, 25-29 August 1986, pp. 1999-2011.

22. W. R. Amos and C. J. Goebel, "Assembly of Radioisotope Heat Sources and Thermoelectric Generators for Galileo and UIysses Missions", Space Nuclear Power Systems 1989, edited by M. S. El-Genk and M. D. Hoover, Orbit Book Company, Malabar, Florida (1992), pp. 25-37.

23. G. R. Ambrose, R.D.Cockfield, and C. E. Kelly, F1 Flight Unit RTG Engineering Report, GESP 7192, Rev. A, General Electric Co. (now Martin Marietta Astro Space), King of Prussia, Pennsylvania, (18 June 1985).

24. G. R. Ambrose, R. D. Cockfield, and C. E. Kelly, F3 Flight Unit RTG Engineering Report, GESP 7202, Rev. A, General Electric Co. (now Martin Marietta Astro Space), King of Prussia, Pennsylvania (14 October 1985). 
25. G. R. Ambrose, R. D. Cockfield, and C. E. Kelly, F4 Flight Unit RTG Engineering Report, GESP 7199, Rev. A, General Electric Co. (now Martin Marietta Astro Space), King of Prussia, Pennsylvania (20 September 1985).

26. G. R. Ambrose, R. D. Cockfield, and C. E. Kelly, F5 Flight Unit RTG Engineering Report, GESP 7193, General Electric Co. (now Martin Marietta Astro Space), King of Prussia, Pennsylvania (19 July 1985).

27. G. R. Ambrose, R. D. Cockfield, and C. E. Kelly, Qualification Unit RTG Engineering Report, GESP 7185, Rev. “C”, General Electric Co. (now Martin Marietta Astro Space), King of Prussia, Pennsylvania (21 June 1985).

28. G. L. Bennett, J. J. Lombardo, and B. J. Rock, "Power Performance of the GeneralPurpose Heat Source Radioisotope Thermoelectric Generator", Space Nuclear Power Systems 1986, edited by M. S. El-Genk and M. D. Hoover, Orbit Book Company, Malabar, Florida, pp. 437-450 (1987).

29. Final Report for the General Purpose Heat Source - Radioisotope Thermoelectric Generator Program, GESP-7209, General Electric Company (now Martin Marietta Astro Space), Philadelphia, Pennsylvania (1 February 1991).

30. R. J. Hemler, C. E. Kelly, and J. F. Braun, "Flight Performance of Galileo and Ulysses RTGs", Proceedings of the Ninth Symposium on Space Nuclear Power Systems, held in Albuquerque, New Mexico, 12-16 January 1992, American Institute of Physics Conference Proceedings 246, Part One, pp. 171176.

31. J. Lotfreda, "TEG 2: A Modified Version of the LOLLIPOPS Computer Program", Internal memorandum PIR ISAO MHW 4663, General Electric Company (now Martin Marietta Astro Space), King of Prussia, Pennsylvania, 4 October 1973.

32. G. L. Bennett, C. W. Whitmore, and W. R.
Amos, "On the Development of the Power Sources for the Ulysses and Galileo Missions", Proceedings of the European Space Power Conference, held in Madrid, Spain, 26 October 1989 (European Space Agency publication ESA SP-294, August 1989).

33. R. J. Hemler, C. E. Kelly, P. M. Klee, and S. Loughlin, "Flight Performance of Galileo and Ulysses RTGs", IECEC Paper No. 93298 prepared for the 28th Intersociety Energy Conversion Engineering Conference, held in Atlanta, Georgia, 8-13 August 1993 (not in Proceedings but available from Martin Marietta Corporation, King of Prussia, Pennsylvania).

34. G. L. Bennett and R. W. Campbell, uPerformance of the Radioisotope Thermoelectric Generators on the Galileo and Ulysses Missions", Proceedings of the European Space Power Conference (European Space Agency document ESA WPP-054, August 1993) held in Graz, Austria, 23-27 August 1993, pp. 225-229.

35. G. L. Bennett, R. W. Campbell, R. J. Hemler, and L. R. Putnam, "Status Report on Performance of Radioisotope Thermoelectric Generators Using Silicon Germanium Thermoelectric Elements", AIAA 94-4127, Proceedings of the 29th Intersociety Energy Conversion Engineering Conference, held in Monterey, California, 7-12 August 1994.

36. C. E. Kelly, "MHW RTG Performance During LES $8 / 9$ and Voyager Missions", Transactions of the Fourth Symposium on Space Nuclear Power Systems, CONF870102--Summs., held in Albuquerque, New Mexico, 12-16 January 1987, pp. 197200, Institute for Space Nuclear Power Studies, University of New Mexico, Albuquerque, New Mexico.

37. G. L. Bennett, J. J. Lombardo, and B. J. Rock, "U.S. Radioisotope Thermoelectric Generator Space Operating Experience (June 1961 - December 1982)", paper 839171, Proceedings of the 18th Intersociety Energy Conversion Engineering Conference, held in Orlando, Florida, 21-26 August 1983, pp. 
1.044-1055. (Reprinted as "US Radioisotope

Thermoelectric Generators in Space" in The

Nuclear Engineer, 25(2): 49-58,

March/April 1984.) 


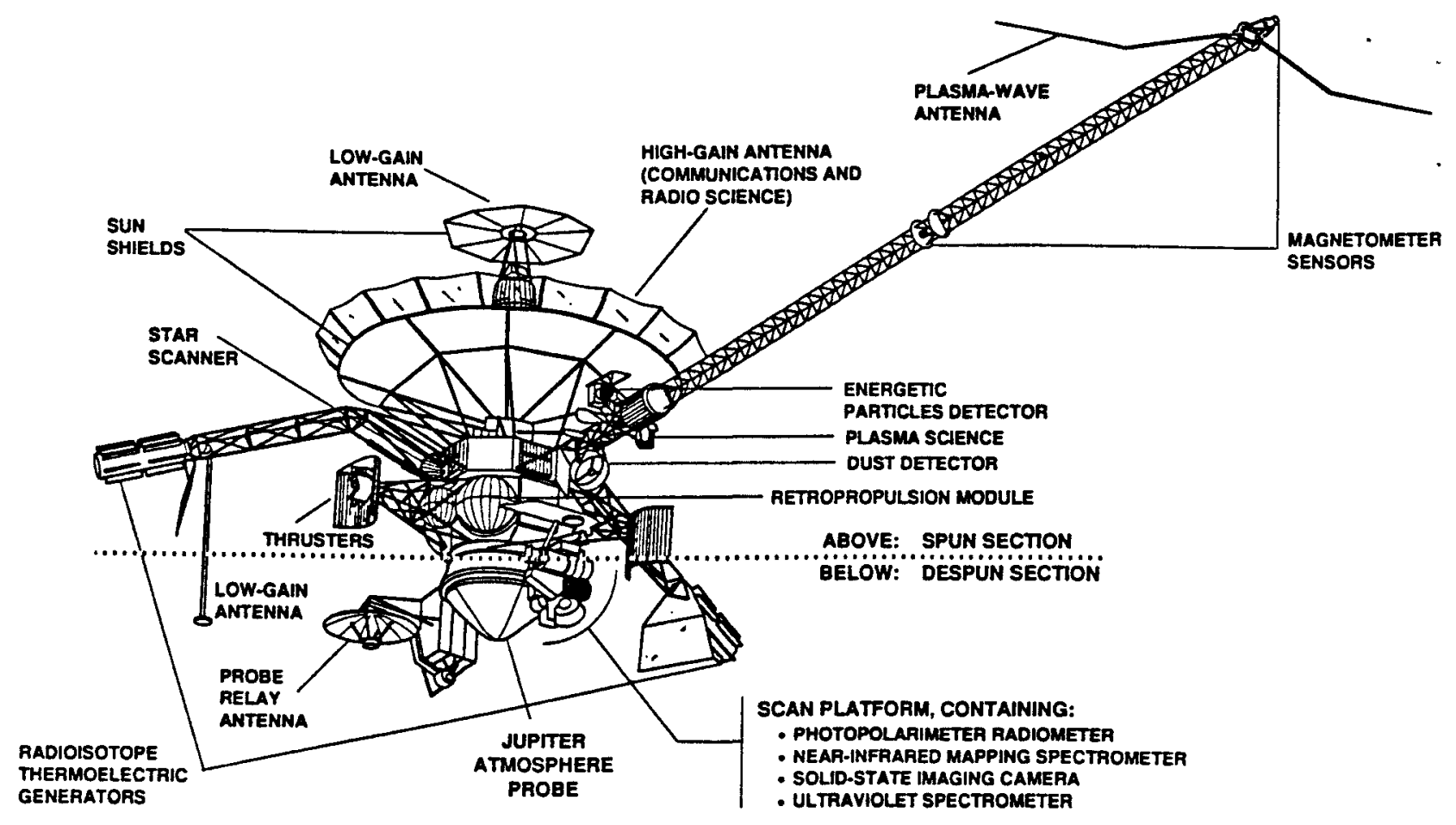

\section{Figure 1. Galileo Spacecraft Orbiter and Probe With the Two GPHS-RTGs Shown Mounted on the Two Booms.}

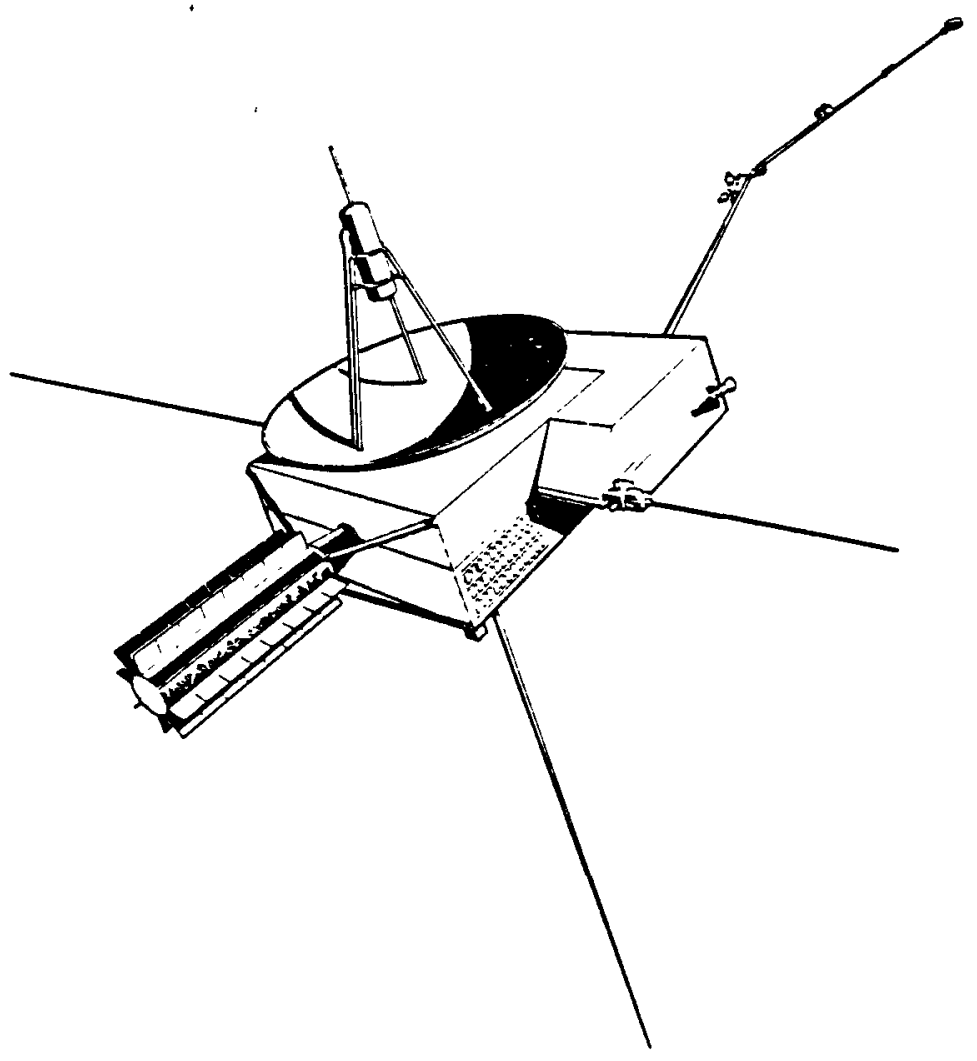

Figure 2. Ulysses Spacecraft With the GPHS-RTG Mounted on the Side. 


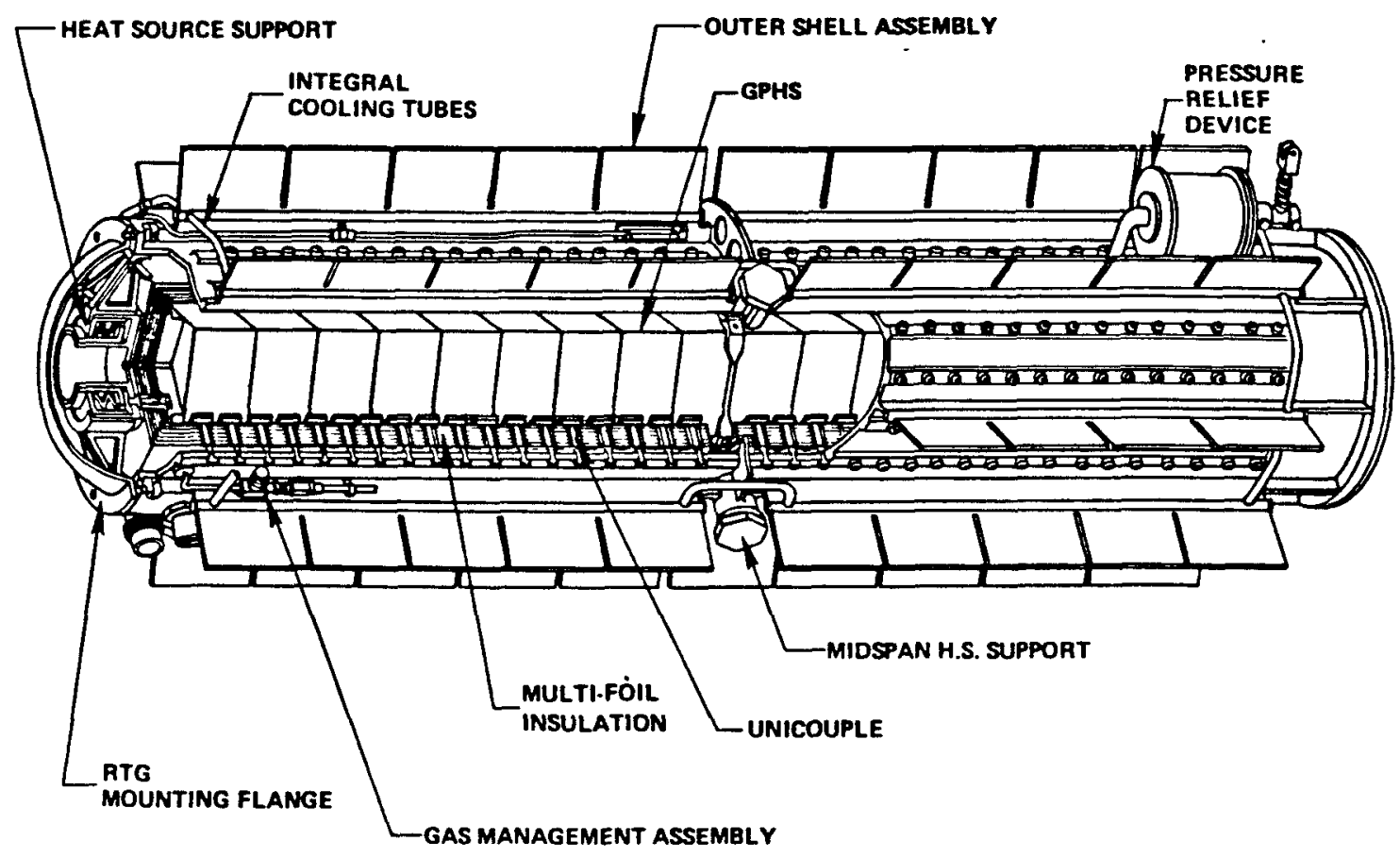

Figure 3. Cutaway of the General-Purpose Heat Source Radioisotope Thermoelectric Generator (GPHS-RTG).

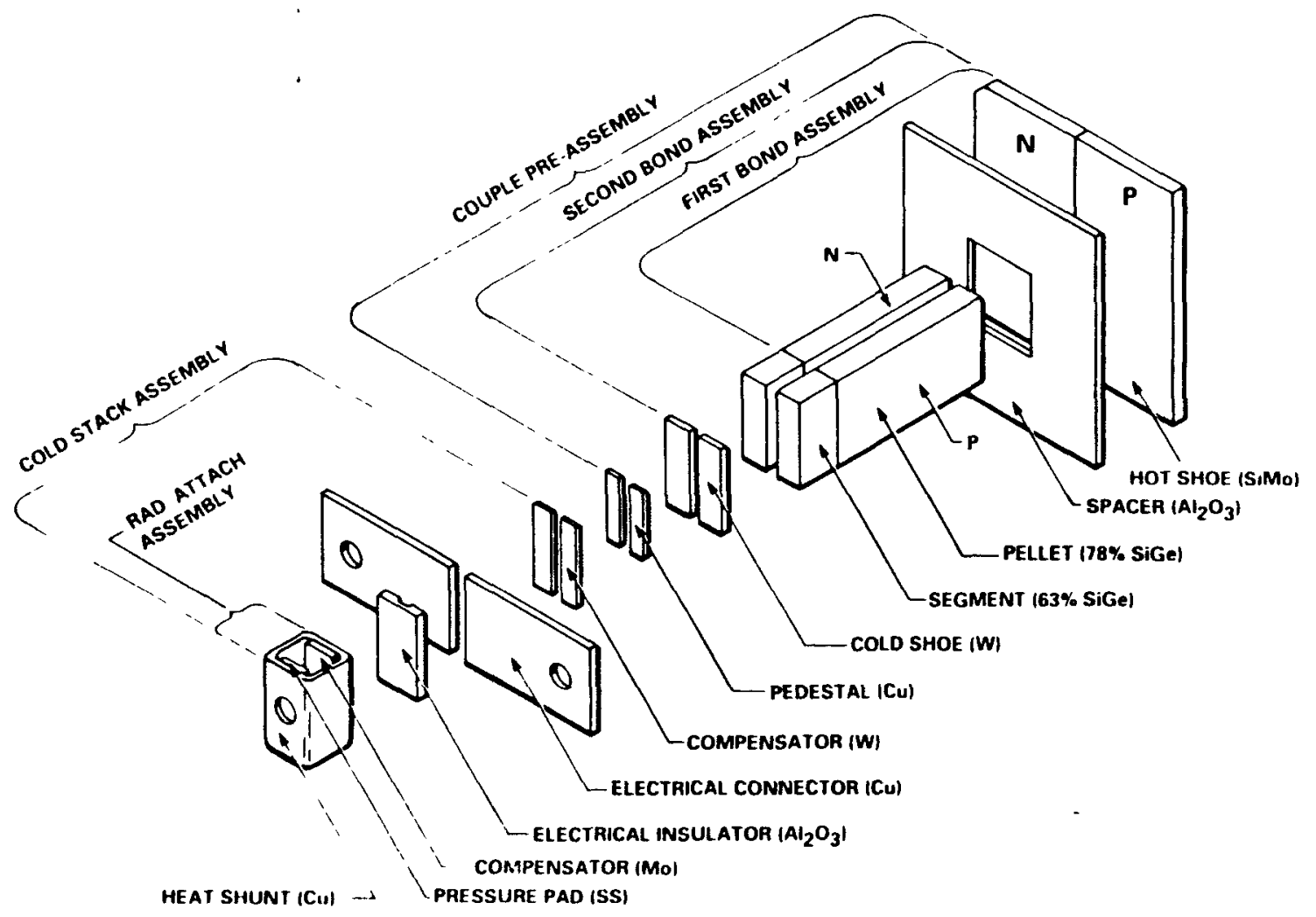

Figure 4. Exploded View of the Silicon-Germanium Thermoelectric Element (Unicouple) Used in the GPHS-RTG. 


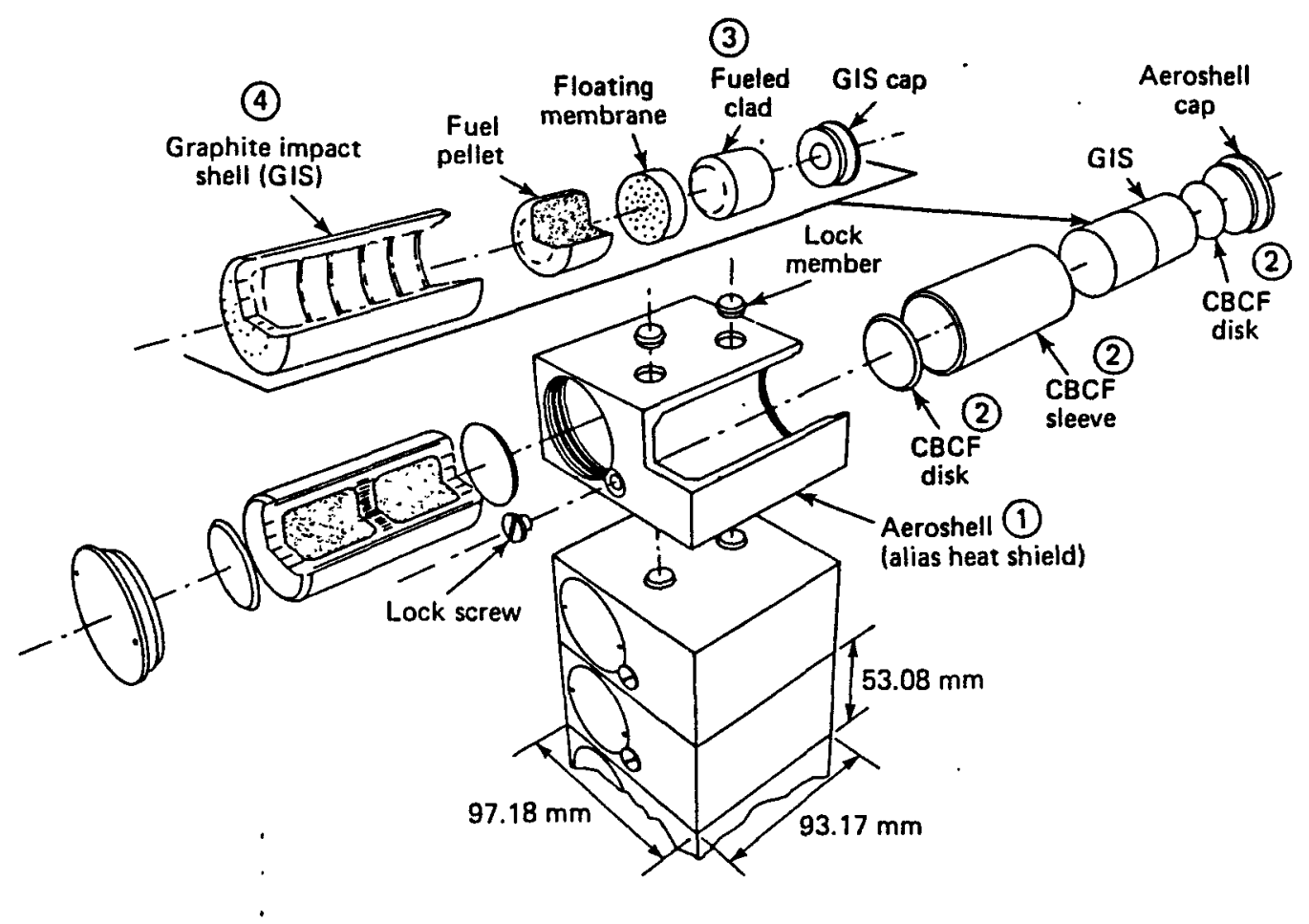

Figure 5. Cutaway View of the General-Purpose Heat Source (GPHS) Module Components and Assemblies.
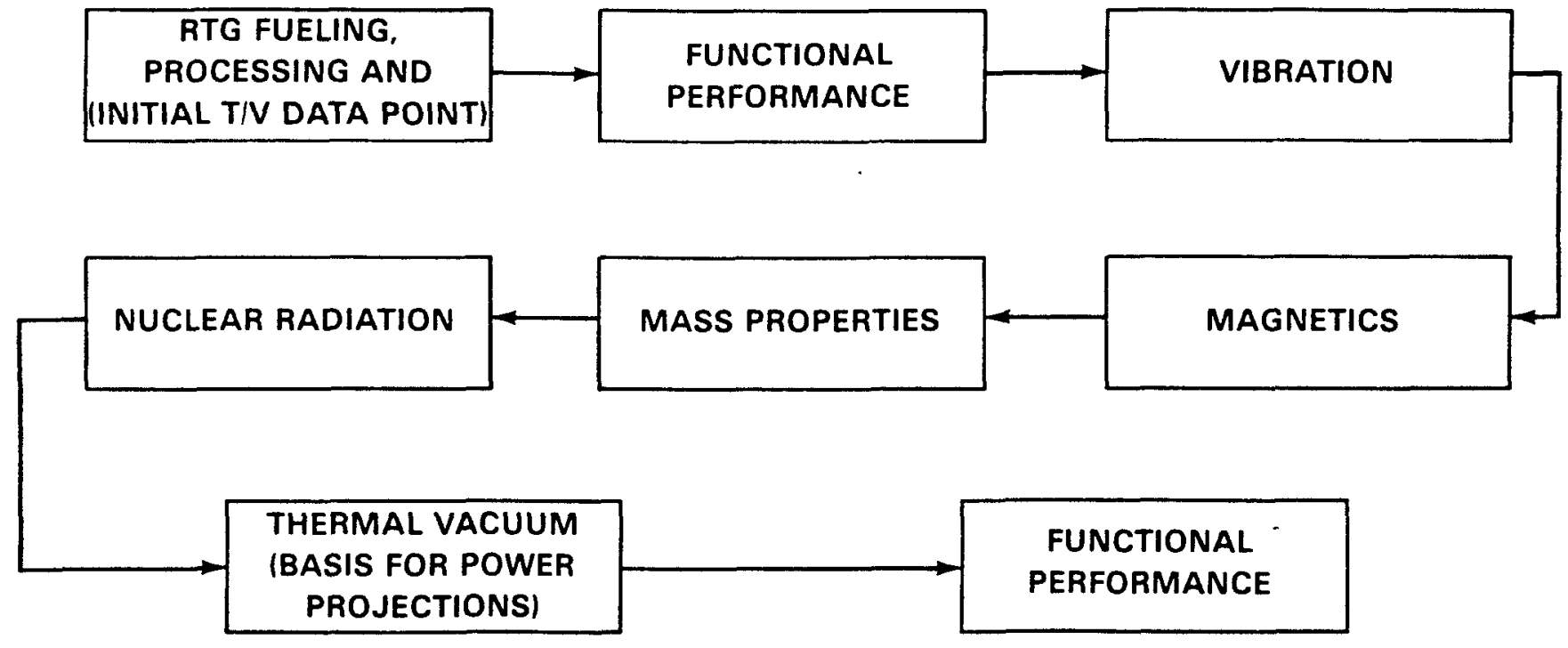

Figure 6. Performance Sequence for GPHS-RTG Assembly and Testing. 

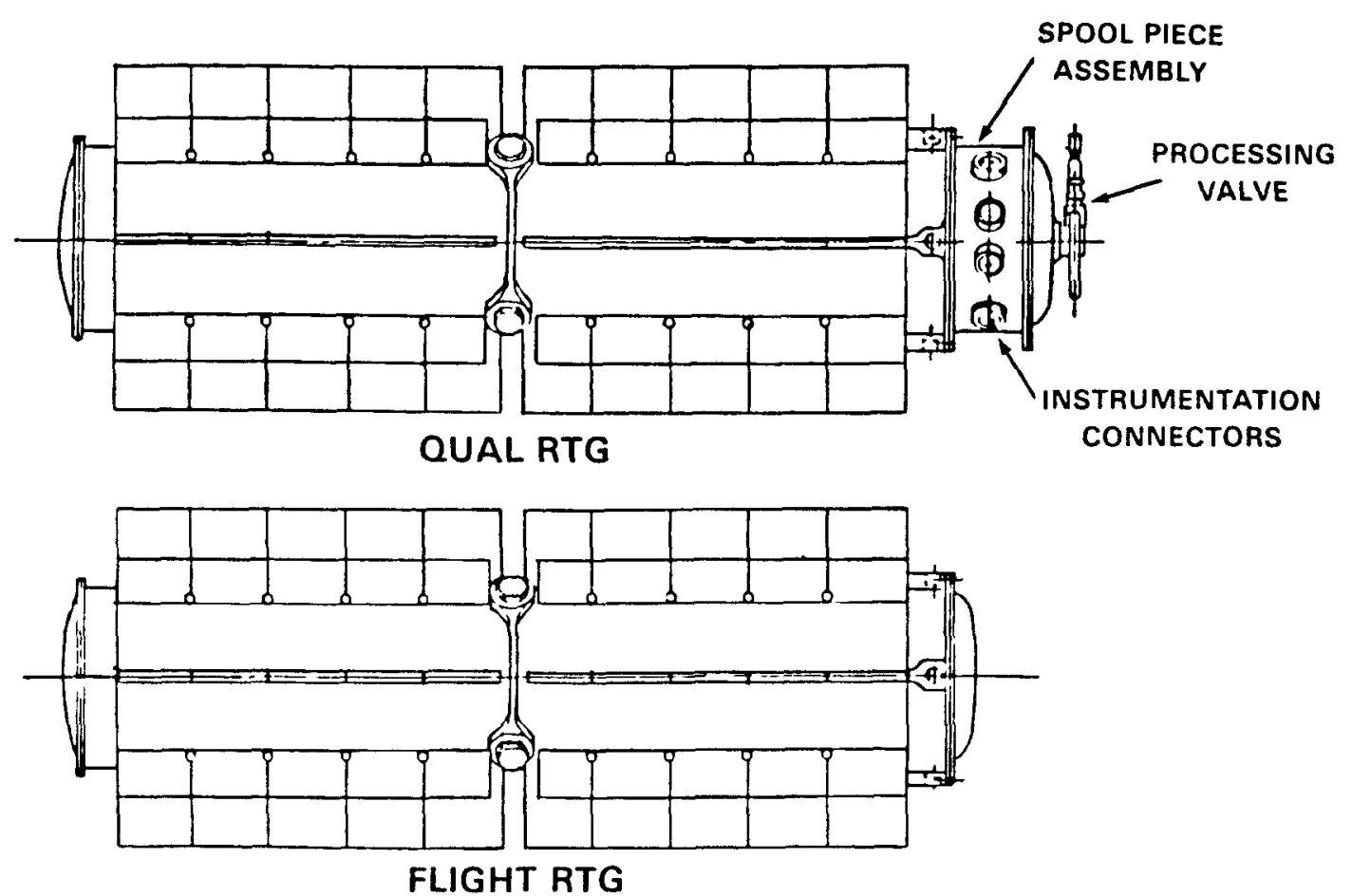

Figure 7. Comparison of Qualification and Flight RTG Configurations for the GPHS-RTG.

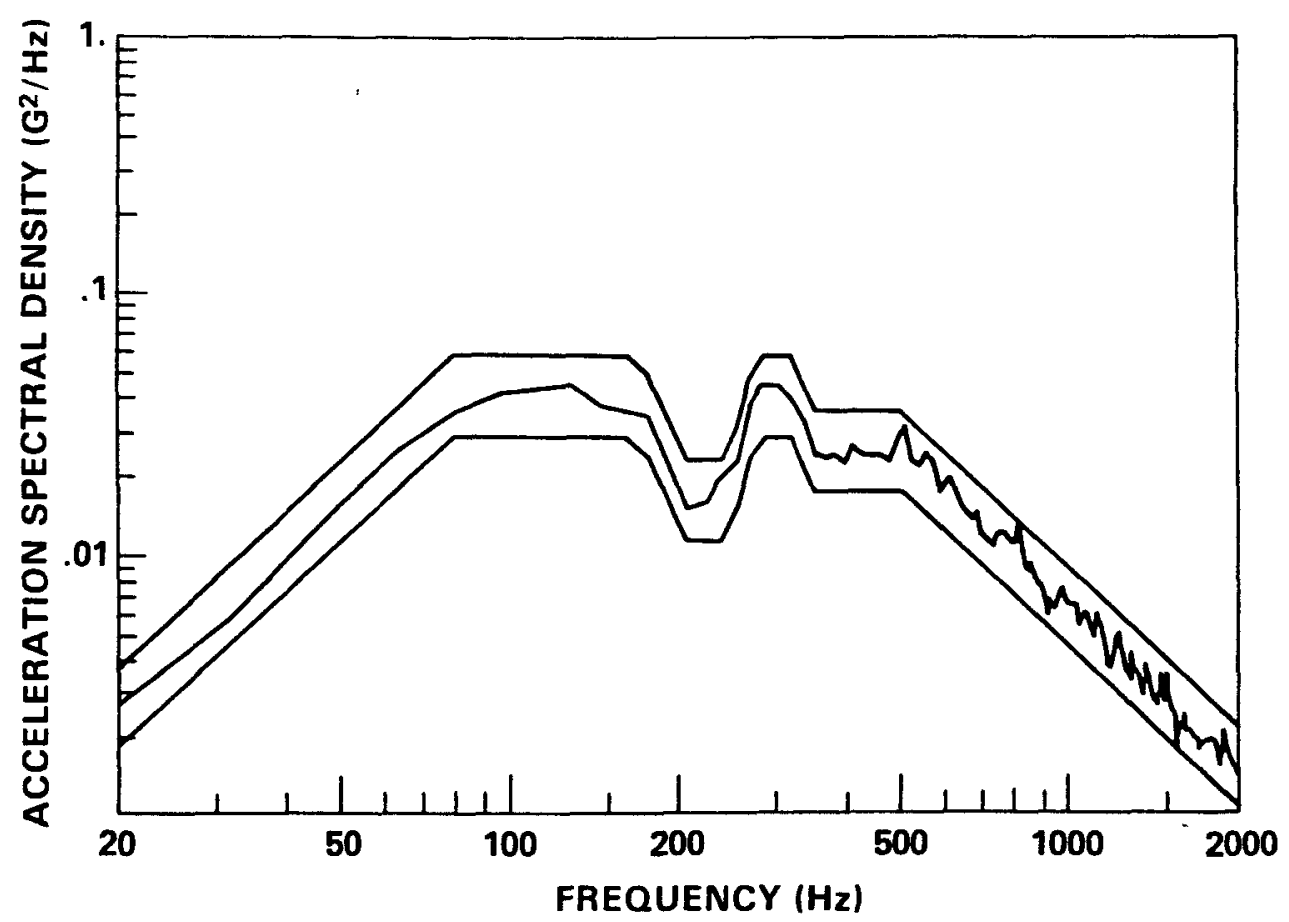

Figure 8. Flight Acceptance Random Vibration Test Spectra for F3 GPHS-RTG -- Lateral Axis

$$
\left(\text { Total } G_{r m s}=4.84\right)
$$




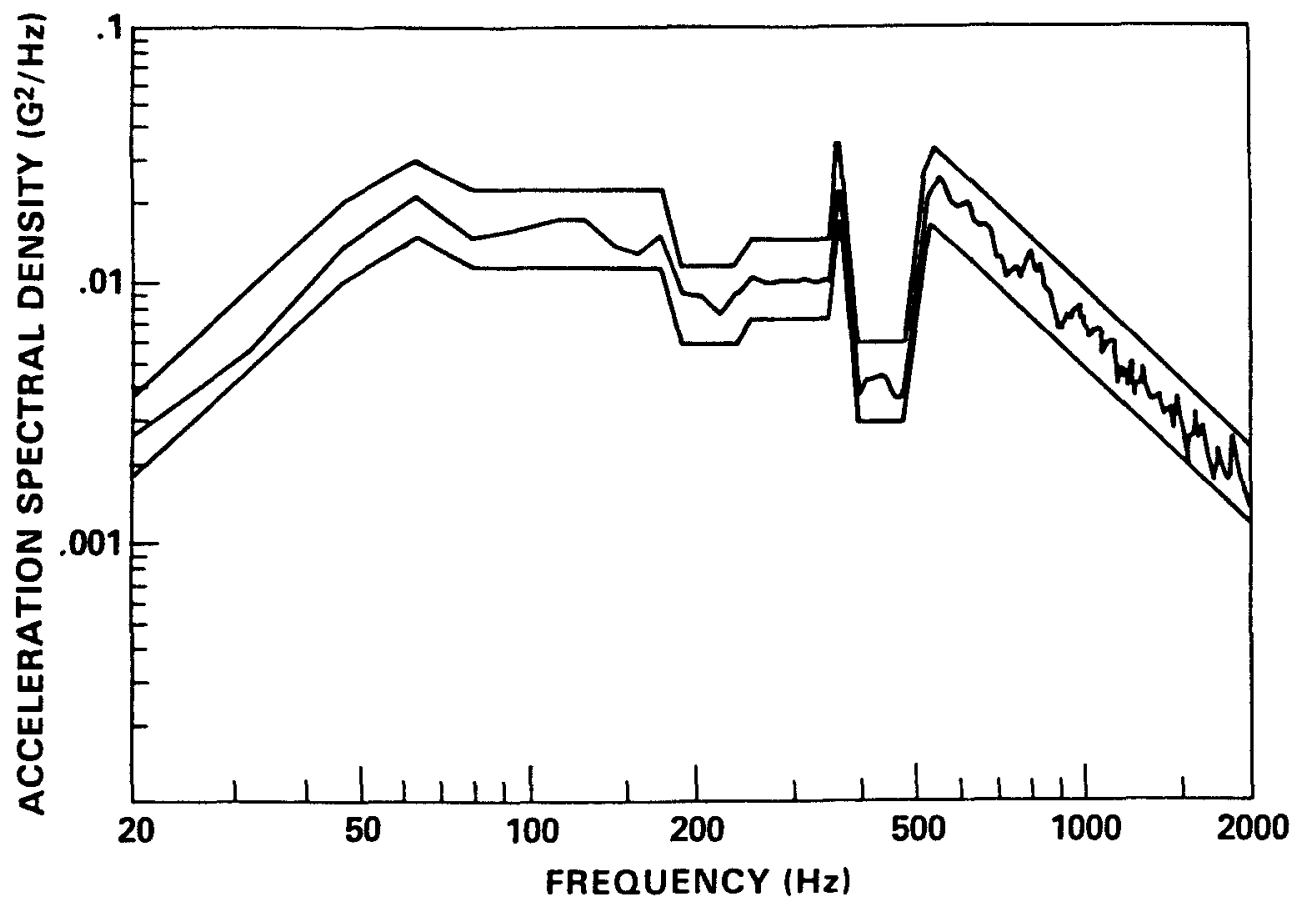

Figure 9. Flight Acceptance Random Vibration Test Spectra for F3 GPHS-RTG Longitudinal Axis.

(Total $G_{r m s}=3.85$ )

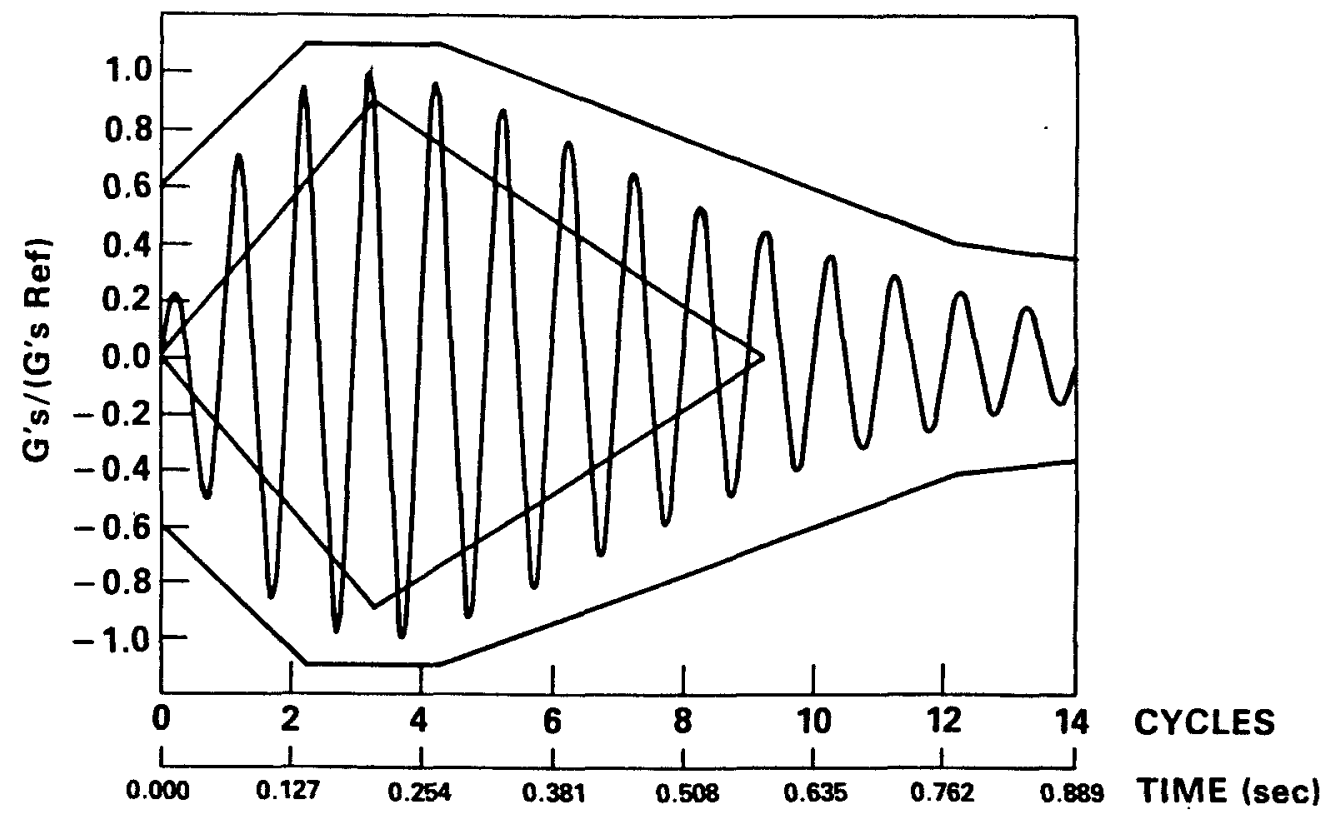

Figure 10. Flight Acceptance Transient Pulse at $15.84 \mathrm{~Hz}$ (Y-axis) for F3 GPHS-RTG. ( $G$ 's Ref $=6.50 ;$;'s Peak $=6.55$ ) 


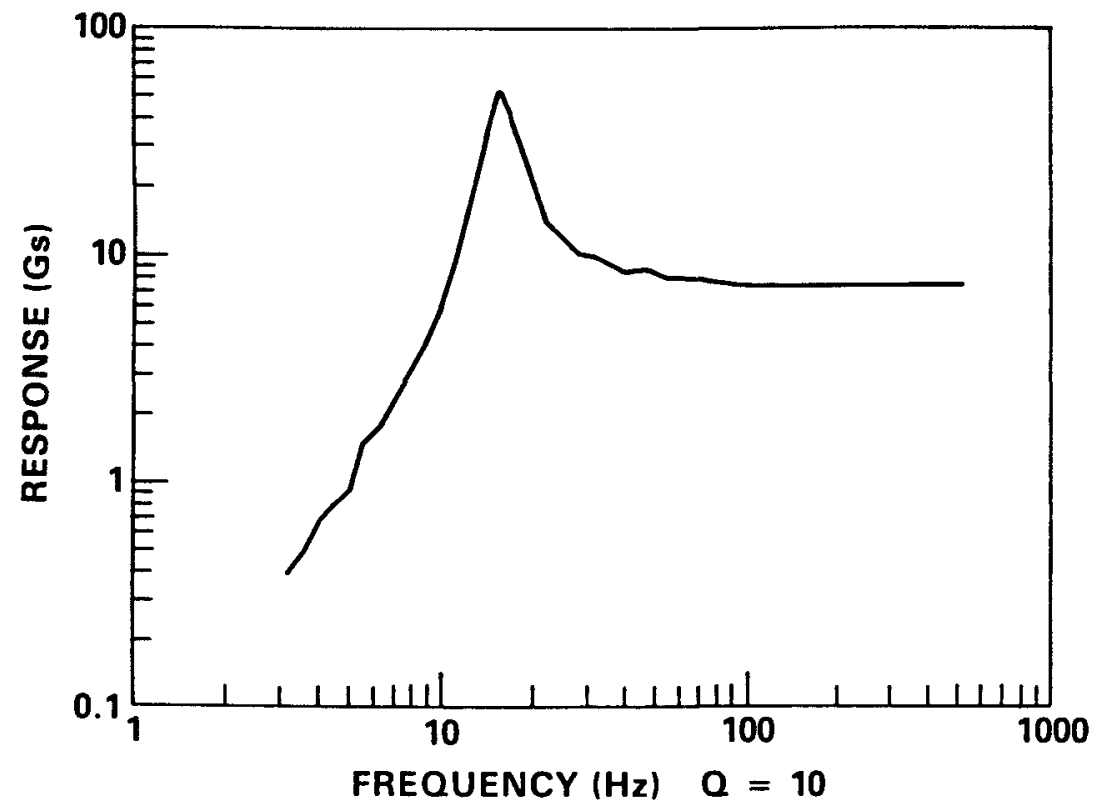

Figure 11. Fllght Acceptance Shock Response Spectrum for F3 GPHS-RTG

(15.84 Hz, Y-axls). (G's Ref $=6.50$; G's Poak = 6.55)

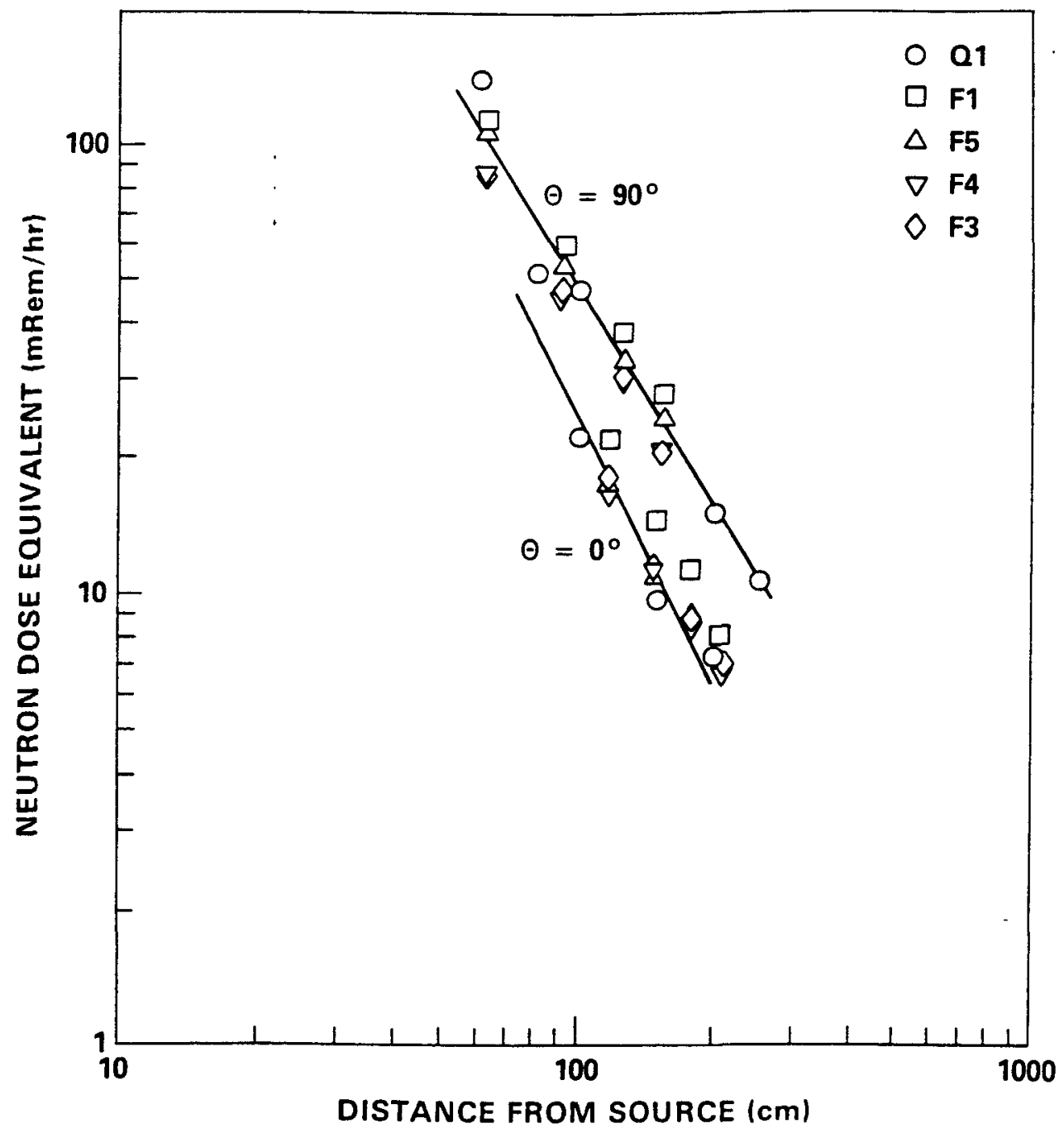

Figure 12. Neutron Radiation Measurements for Flight GPHS-RTGs Compared With Qualification RTG. 


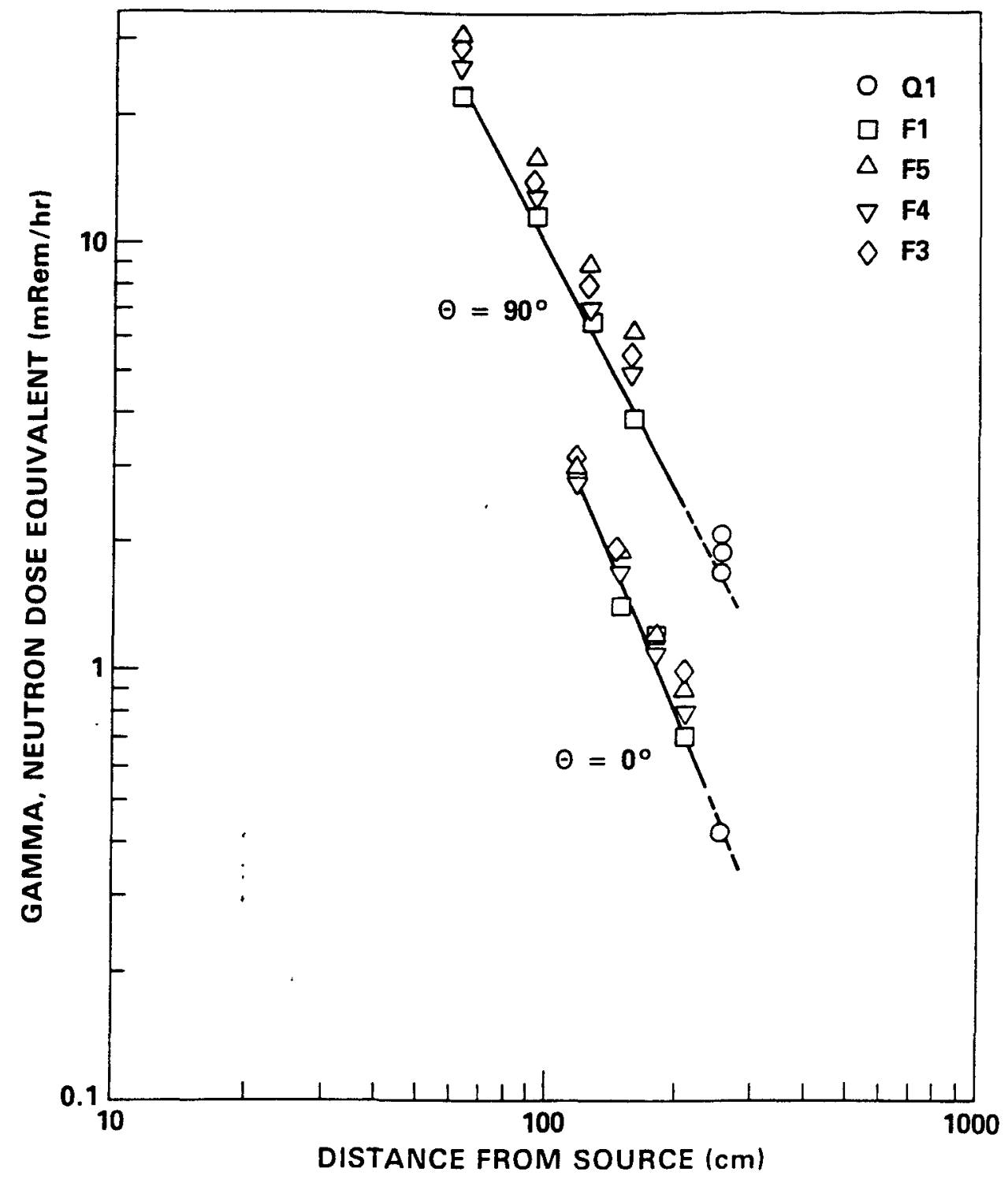

Figure 13. Gamma Radiation Measurements for Flight GPHS-RTGS Compared With Qualification RTG.

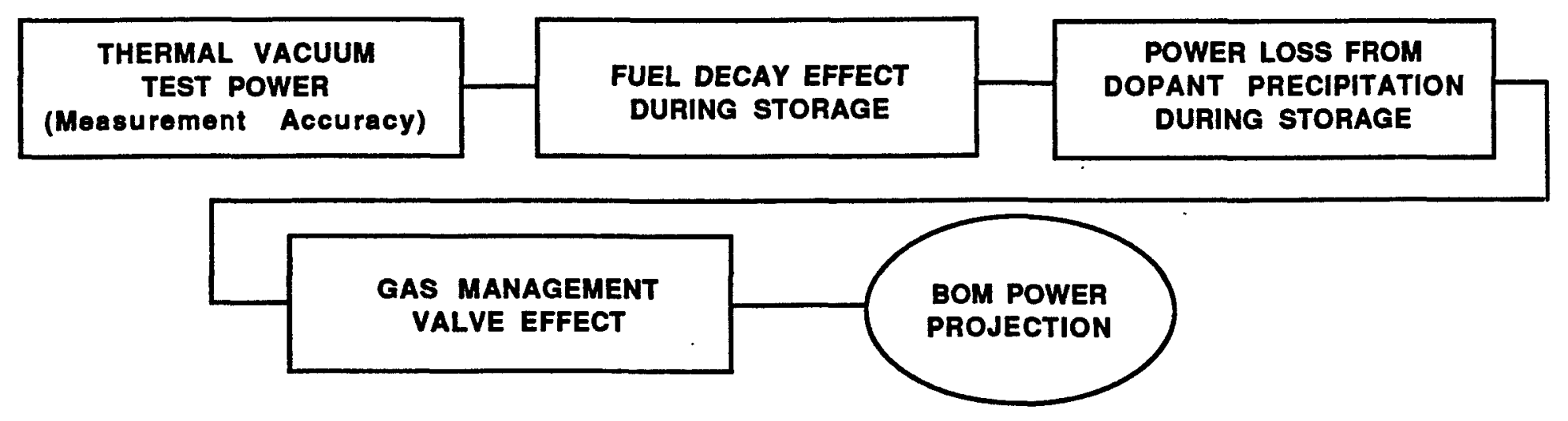

Figure 14. Basis for Projecting the Beginning of Mission (BOM) Power. 


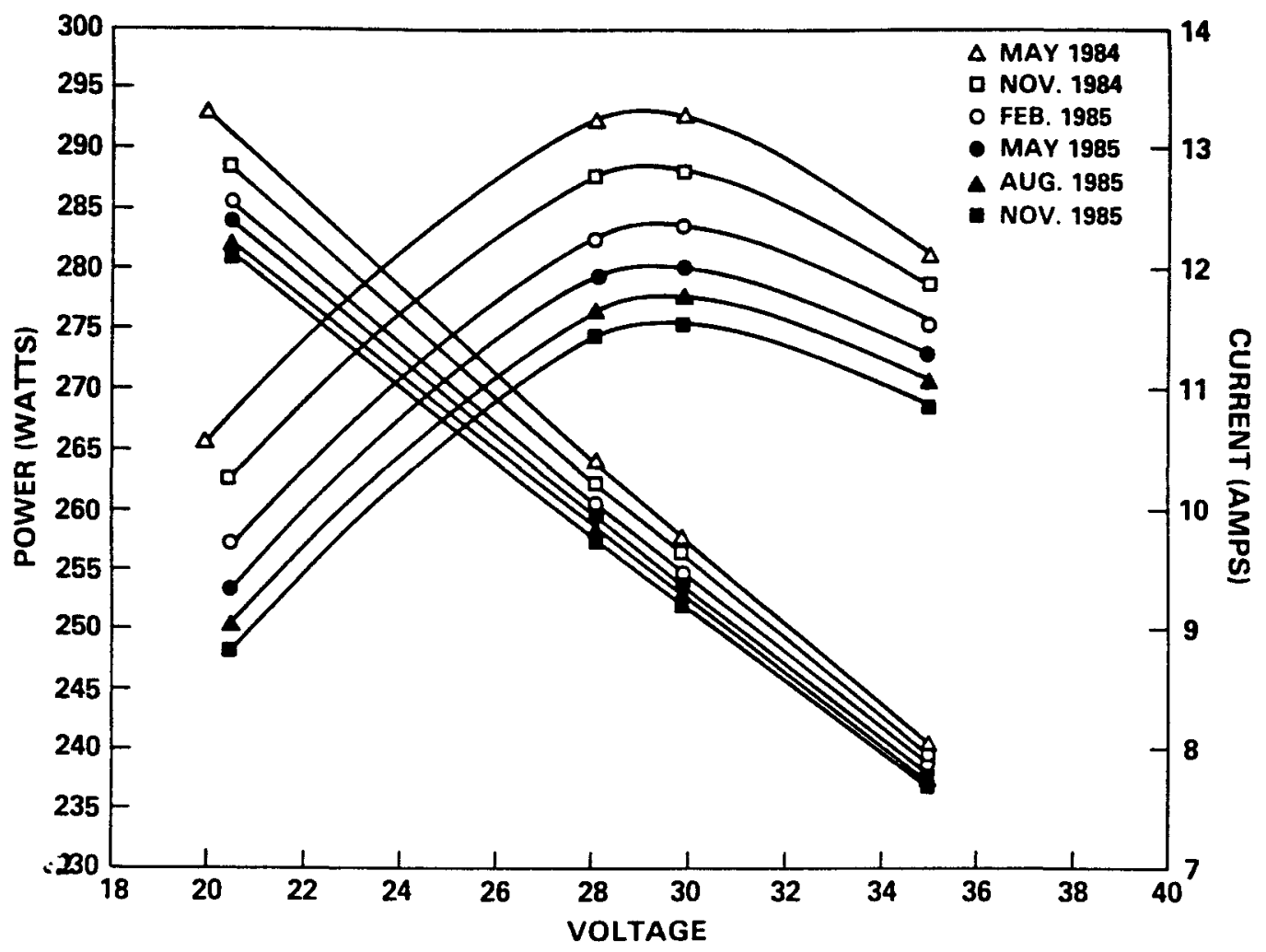

FIgure 15. GPHS-RTG Quallfication Unit Current-Voltage-Power (I-V-P) Map at Different TImes In the LIfe Test.

(Note: The Qualification Unlt was operated for $>53,000$ hours.)

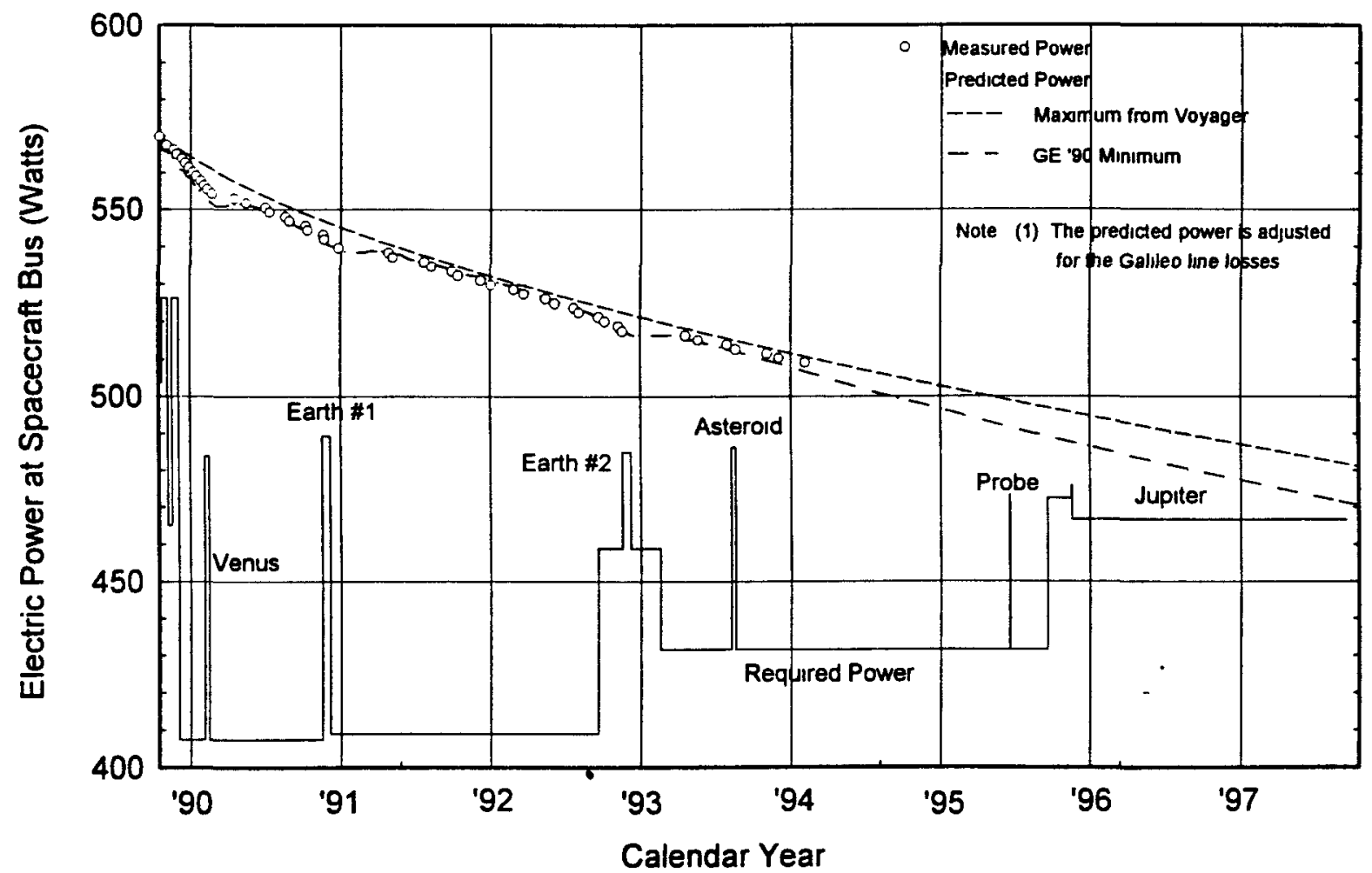

Figure 16. Measured and Predicted Power Output From the Two GPHS-RTGs on the Galileo Spacecraft Compared to the Power Requirements. 


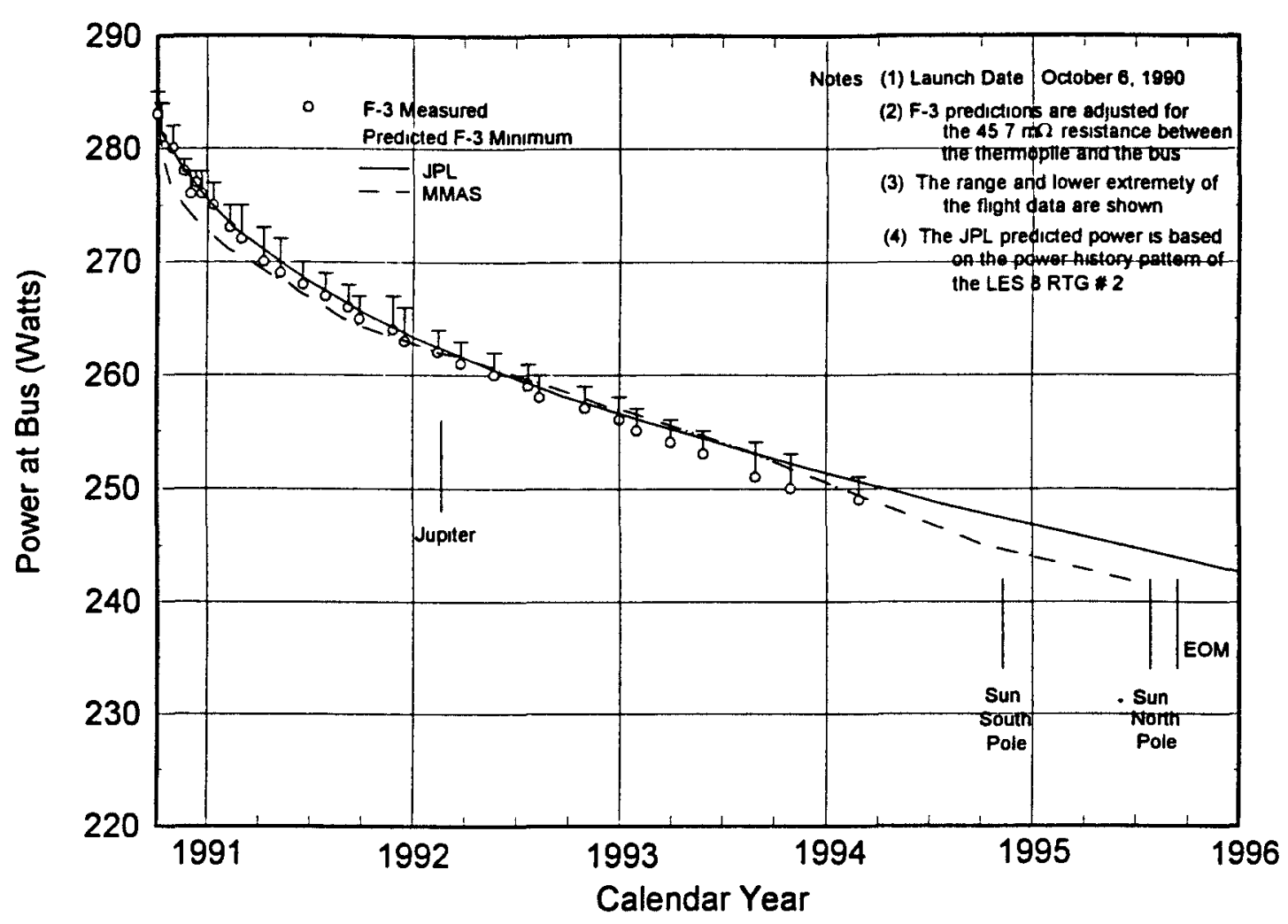

Figure 17. Measured and Predicted Power Output From the GPHS-RTG on the Ulysses Spacecraft.

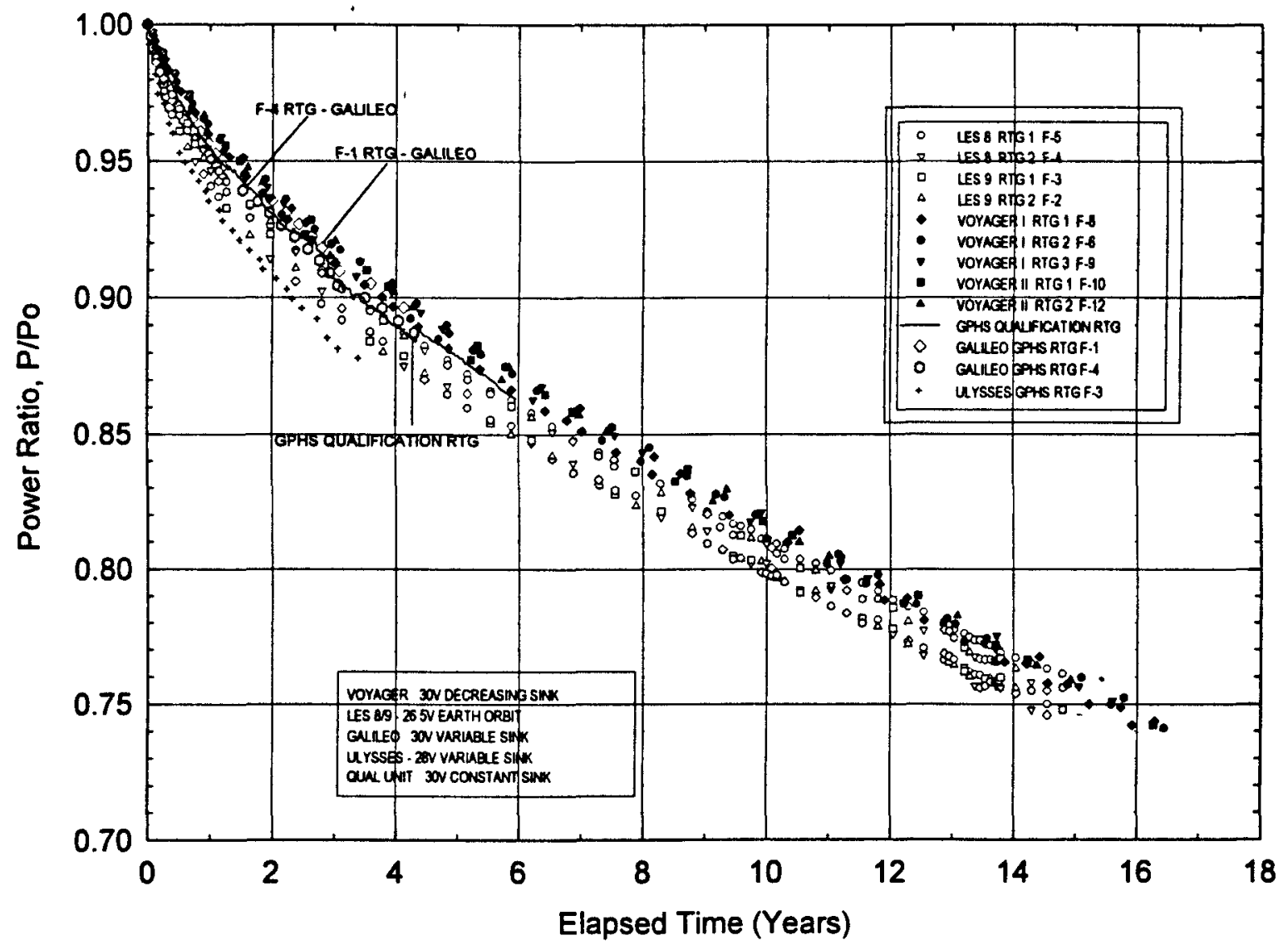

Figure 18. Comparison of All Silicon-Germanium RTG Power Data. 
Table 1. GPHS-ETG Acceptance Performance.

PARAMETER

$\begin{array}{lllll}\text { REQUIREMENT } & \text { F1 } & \text { F3 } & \text { F4 } & \text { F5 }\end{array}$

BOL POWER, WATTS

$\begin{array}{ccccc}\geqslant 293 & 294.6 & 294.4 & 293.8 & 295.4 \\ 30 & 30 & 30 & 30 & 30 \\ >1000 & 2000 & 2100 & 3100 & 5000 \\ >130 & 151.8 & 156.0 & 154.7 & 158.7 \\ \leqslant 67 & 66.25 & 66.05 & 66.34 & 65.92 \\ \geqslant 30 & 300 & 1000 & 1000 & 300\end{array}$

VOLTAGE, VOLTS

SHUNT RESISTANCE, OHMS

POWER IN ARGON, WATTS

MASS, POUNDS

$\geqslant 30$

300

NORMALIZED TO $4400 \mathrm{~W}_{\mathrm{T}}$

Table 2. Ulysses RTG Critical Load Conditions.

\begin{tabular}{|c|c|c|c|c|c|c|c|c|}
\hline \multirow[b]{2}{*}{$\begin{array}{l}\text { FLIGHT } \\
\text { CONDITION }\end{array}$} & \multirow[b]{2}{*}{$\begin{array}{l}\text { THERMAL } \\
\text { CONDITION }\end{array}$} & \multicolumn{2}{|c|}{ LOADS $^{A}$} & \multicolumn{3}{|c|}{ REQUIRED INTEGRITY } & \multirow{2}{*}{$\begin{array}{l}\text { MINIMUM } \\
\text { MARGIN } \\
\text { OF } \\
\text { SAFETY }\end{array}$} & \multirow[b]{2}{*}{ BASIS } \\
\hline & & DIRECTION & G's & $\begin{array}{c}\text { OF } \\
\text { SAFETY }\end{array}$ & STRUCTURAL & FUNCTIONAL & & \\
\hline LIFTOFF & COOLED & $\begin{array}{l}x \\
y \\
z\end{array}$ & $\begin{array}{l}56 \\
73 \\
50\end{array}$ & $\begin{array}{l}10 \text { LIMIT } \\
14 \text { ULT }\end{array}$ & YES & YES & $\begin{array}{l}\text { ACCELERATION } \\
X . Y+11 \text { LIMIT } \\
X . Y+55 \text { ULT } \\
Z,+50 \text { LIMIT } \\
Z,+32 \text { ULT }\end{array}$ & $\begin{array}{l}\text { QUAL } \\
\text { TEST }\end{array}$ \\
\hline $\begin{array}{l}\text { CENTAUR } \\
\text { BURN } \\
\text { OUT }\end{array}$ & UNCOOLED & $\begin{array}{l}x \\
y \\
z\end{array}$ & $\begin{array}{l}05 \\
58 \\
06\end{array}$ & $\begin{array}{l}10 \text { LIMIT } \\
125 \text { ULT }\end{array}$ & YES & YES & $\begin{array}{l}\begin{array}{c}\text { HEAT SOURCE } \\
\text { PRELOAD }\end{array} \\
\text { F3, }+1 \text { LIMIT } \\
\text { F3, + } 7 \text { ULT } \\
\text { F4 + } 7 \text { LIMIT } \\
\text { F4 + } 3 \text { ULT }\end{array}$ & ANALYSIS \\
\hline $\begin{array}{l}\text { NORMAL } \\
\text { LANDING }\end{array}$ & UNCOOLED & $\begin{array}{l}X \\
y \\
Z\end{array}$ & $\begin{array}{l}82 \\
77 \\
60\end{array}$ & $\begin{array}{l}10 \text { LIMIT } \\
14 \text { ULT }\end{array}$ & YES & NO & $\begin{array}{l}\text { INBOARD MOUNTS } \\
+51 \text { LIMIT } \\
+48 \text { ULT }\end{array}$ & ANALYSIS \\
\hline
\end{tabular}

- simultaneously APPLIED

- MARGIN OF SAFETY = ALLOWABLE LOAD OR STRESS

(FACTOR OF SAFETY) (APPLIED LOAD OR STRESS) 
Table 3. Galileo RTG Critical Load Conditions.

\begin{tabular}{|c|c|c|c|c|c|c|c|c|}
\hline \multirow{2}{*}{$\begin{array}{c}\text { FLIGHT } \\
\text { CONDITION }\end{array}$} & \multirow{2}{*}{$\begin{array}{l}\text { THERMAL } \\
\text { CONDITION }\end{array}$} & \multicolumn{2}{|c|}{ LOADS } & \multicolumn{3}{|c|}{ REQUIRED INTEGAITY } & \multirow{2}{*}{$\begin{array}{l}\text { MINIMUM } \\
\text { MARGIN } \\
\text { OF } \\
\text { SAFETY* }\end{array}$} & \multirow[b]{2}{*}{ BASIS } \\
\hline & & DIRECTION & G's & SAFETY & STRUCTUAAL & FUNCTIONAL & & \\
\hline LIFTOFF & COOLED & $\begin{array}{l}X \\
y \\
z\end{array}$ & $\begin{array}{r}14.2 \\
7.7 \\
8.6\end{array}$ & $\begin{array}{l}1.0 \text { LIMIT } \\
1.4 \text { ULT }\end{array}$ & YES & YES & $\begin{array}{l}\text { ACCELERATION } \\
x,+.58 \text { LIMIT } \\
X,+.13 \text { ULT } \\
z_{,}+2.5 \text { LIMIT } \\
z_{,}+1.5 \text { ULT }\end{array}$ & $\begin{array}{l}\text { ANALYSIS AND } \\
\text { TEST }\end{array}$ \\
\hline $\begin{array}{l}\text { CENTAUR } \\
\text { BURN } \\
\text { OUT }\end{array}$ & UNCOOLED & $\begin{array}{l}x \\
y \\
z\end{array}$ & $\begin{array}{l}0.7 \\
2.5 \\
3.0\end{array}$ & $\begin{array}{l}1.0 \text { LIMIT } \\
1.25 \text { ULT }\end{array}$ & YES & YES & 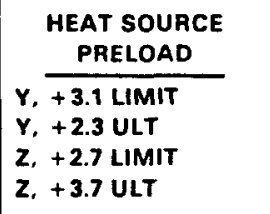 & ANALYSIS \\
\hline $\begin{array}{l}\text { NORMAL } \\
\text { LANDING }\end{array}$ & UNCOOLED & $\begin{array}{l}\mathbf{X} \\
\mathbf{Y} \\
\mathbf{z}\end{array}$ & $\begin{array}{r}2.4 \\
6.6 \\
15.5\end{array}$ & $\begin{array}{l}1.0 \text { LIMIT } \\
1.4 \text { ULT }\end{array}$ & YES & No & $\begin{array}{l}\text { INBOARD MOUNTS } \\
+9.3 \text { LIMIT } \\
+9.1 \text { ULT } \\
\text { MID RING MOUNTS } \\
+3.3 \text { LIMIT } \\
+3.2 \text { ULT }\end{array}$ & ANALYSIS \\
\hline
\end{tabular}

- MARGIN OF SAFETY $=\frac{\text { ALLOWABLE LOAD OR STRESS }}{\text { (FACTOR OF SAFETY) (APPLIED LOAD OR STAESS) }}-1$

- CET.1 AND ENGINEERING UNIT DYNAMIC TESTS

Table 4. Typical GPHS-RTG Magnetic Field.

REQUIREMENT - 30 NT AT 1 METER, 1 NT AT 2 METERS

MEASUREMENTS AT 1.0 METER

TEST POSITION

$1+\times 30^{\circ}$ UP

$2 \times 2$ PLANE

$3+\times 30^{\circ}$ DOWN

$4+X 60^{\circ}$ DOWN

5 YZ PLANE

$6-X 60^{\circ}$ UP

MEASUREMENTS AT 1.5 METER

$1+\times 30^{\circ}$ UP

$2 \quad X Z$ PLANE

$3+\times 30^{\circ}$ DOWN

$4+\times 60^{\circ}$ DOWN

5 YZ PLANE

$6-X 60^{\circ}$ UP

\section{ZERO RTG CURRENT GAMMA}

17

18

18

13

16

19

2

3

3

2

1

2
FLIGHT-RATED RTG CURRENT

GAMMA
62
97
114
68
61
63

13

20

23

16

10

8 


\section{Table 5. GPHS-RTG Mass Properties Summary.}

\begin{tabular}{|c|c|c|c|c|c|c|}
\hline \multirow[b]{2}{*}{ PARAMETER } & \multirow[b]{2}{*}{ REQUIREMENT } & \multicolumn{5}{|c|}{ TEST PERFORMANCE } \\
\hline & & F1 & $\mathbf{F 3}$ & $\mathbf{F a}$ & $\mathbf{F 4}$ & $F$ \\
\hline $\begin{array}{l}\text { MASS. Ko } \\
\text { CENTER OF MASS }\end{array}$ & $\begin{array}{l}5624 \\
\text { WITHIN RT CYLINDER } \\
\text { O } 635 \mathrm{~cm} \text { DIA } \times 127 \mathrm{~cm} \text { LO } \\
\text { KNOWLEDGE WITHIN } \\
\text { O } 152 \mathrm{~cm} \text { DIA SPHERE } \\
\text { ACCURACY OOS KO } \mathrm{M}^{2} \\
\text { ACCURACY } 0012 \mathrm{Kg} \mathrm{M}^{2}\end{array}$ & $\begin{array}{l}505 \\
x=+0004 \\
y=+0107 \\
z=-53221 \\
0132011 \\
1 x=5781 \pm 007 \\
1 y=5747-000 \\
1 z=0313 \pm 001 \\
1 x y=00005 \pm 0021 \\
1 y z=0009 \pm 0021 \\
12 x=0007 \pm 0021\end{array}$ & $\begin{array}{l}5581 \\
x=+0003 \\
y=+0130 \\
z=-53183 \\
0132014 \\
1 x=5761 \pm 007 \\
1 y=5739-000 \\
\mid z=0312 \pm 001 \\
1 x y=00004 \pm 0021 \\
1 y z=00016 \pm 0021 \\
\mid 2 x=00019 \pm 0001\end{array}$ & 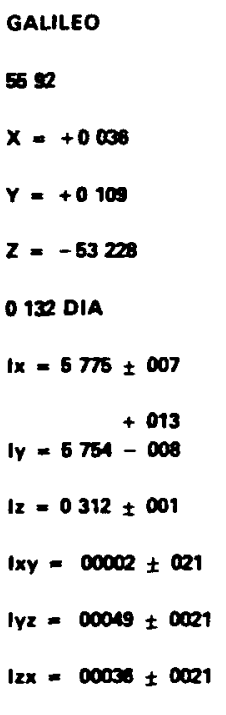 & 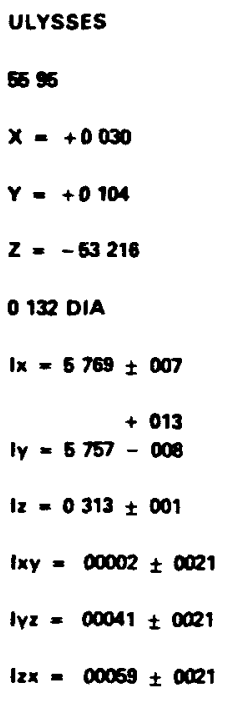 & $\begin{array}{l}5692 \\
x=+0051 \\
y=+0069 \\
z=-53218 \\
0132014 \\
1 x=577 \pm \pm 007 \\
1 y=6751-000 \\
1 z=0312 \pm 001 \\
1 x y=00002 \pm 0021 \\
1 y z=00049 \pm 0021 \\
12 x=00036 \pm 0021\end{array}$ \\
\hline
\end{tabular}

Table 6. GPHS-RTG Thermal Vacuum Performance Comparison.

\section{PARAMETER}

THERMAL INVENTORY, WATTS

DATE

RTG POWER OUTPUT, WATTS

$$
\begin{aligned}
& \text { AS MEASURED } \\
& \text { CORRECTED }
\end{aligned}
$$

NORMALIZED TO $4410 \mathrm{~W}$

LOAD VOLTAGE, VOLTS

OPEN CIRCUIT VOLTAGE, VOLTS

INTERNAL RESISTANCE,

OHMS

SHUNT RESISTANCE,

K OHMS

RTD TEMPERATURE, ${ }^{\circ} \mathrm{C}$

1 - POWER NOT STABILIZED

REQUIREMENT

F1

F3

F4

F4

F5

4460.1

$12 / 14 / 84$

\section{1}

308.2

$>292$

30

302.0

30.02

52.42

2.197

$>1.0$

$<260$

2.2

247
4479.1

$8 / 15 / 85$

$303.1^{1}$

$305.4^{9}$

$297.1^{1}$

28.02

$\mathbf{5 1 . 7 5}$

2.194

2.1

247
4435.2

$7 / 20 / 85$

301.4

303.7

300.7

28.04

51.37

2.169
3.4

246
2.174

2.191

4435.1

$7 / 21 / 85$

4443.5

5/22/85

305.2

307.3

303.3

30.03

29.97

51.94

52.31

3.4

5.6

246

244 